Check for updates

Cite this: RSC Adv., 2018, 8, 20379

\title{
Preparation of polycarboxylic acid-functionalized silica supported Pt catalysts and their applications in alkene hydrosilylation $\uparrow$
}

\begin{abstract}
Dongyun Shao and Youxin Li (iD *
A series of novel immobilized platinum catalysts was prepared by loading Pt onto silica particles modified with polycarboxylic acid groups such as diethylenetriaminepentaacetic acid (DTPA), nitrolotriacetic acid (NTA) and succinic acid (SA). The three modified heterogeneous Pt catalysts were characterized using infrared spectroscopy (IR), transmission electron microscopy (TEM), X-ray photoelectron spectroscopy (XPS), energy dispersive X-ray spectroscopy (EDS) and atomic absorption spectroscopy (AAS). The residual $\mathrm{H}_{2} \mathrm{PtCl}_{6}$ solutions were characterized using ultraviolet spectroscopy (UV). The polycarboxylic acid-functionalized silica supported Pt catalysts were used to catalyze alkene hydrosilylation and 1-hexene was chosen as a model alkene. The data indicated that the catalytic performance was strongly dependent on the properties of the polycarboxylic acid group bonded to the silica particles. Among them, DTPA-functionalized silica supported $\mathrm{Pt}\left(\mathrm{SiO}_{2}\right.$-DTPA-Pt) showed the best catalytic activity and reusability. Furthermore, some hydrosilylation reactions between other linear alkenes (1-heptene, 1-octene, 1-decene, 1-do-decene, 1-tetra-decene, 1-hexa-decene, 1-octa-decene, styrene or cis-hex2-ene), or ring type alkenes (norbornene) with methyldichlorosilane could be catalyzed in the presence of these three Pt catalysts. Their high activities were more than $90 \%$, and their selectivities were more than 99\%, which were apparently better than homogeneous Pt catalysts. In addition, reactions with cyclohexene were also successfully catalyzed by the Pt catalysts. These results indicate that the polycarboxylic acid-functionalized silica gel supported Pt catalysts have potential value in industrial hydrosilylation reactions.
\end{abstract}

Received 1st March 2018 Accepted 18th May 2018 DOI: $10.1039 / c 8 r a 01828 f$ rsc.li/rsc-advances

\section{Introduction}

Platinum catalysts have received much attention from many researchers because of their significant applications in many fields. They can be used to catalyze the hydrosilylation reaction of olefins since Speier et al. ${ }^{1}$ discovered that hexachloroplatinic acid was a very active catalyst for hydrosilylation reactions. Besides, some varieties of Pt catalyst can also be used to catalyze $\mathrm{NO}_{x}$ reduction by hydrogen, ${ }^{2,3}$ hydrogenation processes, ${ }^{\mathbf{4}, \mathbf{5}}$ the oxidation of alcohols, ${ }^{6}$ dehydrogenation reactions ${ }^{7}$ and so forth. Among these reactions, the hydrosilylation of alkenes is a crucial reaction on both the industrial and laboratory scale. It is a carbon-silicon bond forming reaction, providing access to organofunctional silanes and silicones, which are commonly used for the production of cross-linkers, adhesives and

Tianjin Key Laboratory for Modern Drug Delivery and High-Efficiency, Collaborative Innovation Center of Chemical Science and Engineering, School of Pharmaceutical Science and Technology, Tianjin University, Room C412-8, Building 24, 92 Weijin Road, Nankai District, Tianjin 300072, China. E-mail: lyx@tju.edu.cn; Fax: +86-222789-2820; Tel: +86-22-2789-2820

$\dagger$ Electronic supplementary information (ESI) available. See DOI: 10.1039/c8ra01828f polymers. ${ }^{\mathbf{8} 9}$ Today, hydrosilylation reactions are usually activated by homogeneous catalysts such as Speier's catalyst (hexachloroplatinic acid), ${ }^{\mathbf{1}}$ Karstedt's catalyst ${ }^{\mathbf{1 0}}$ and Markó's catalyst $^{11}$ due to their unparalleled catalytic activities. However, these homogeneous Pt catalysts have high cost, poor selectivity $^{\mathbf{1 2}}$ and non reusability and result in environmental pollution. ${ }^{13}$ Moreover, due to their extremely high reactivity, the catalysts often require an inert atmosphere to play a better role and avoid potential risk, which restricts their utility for large scale industrial production.

The development of heterogeneous catalysts with high activity, selectivity and reusability was necessary and had been studied over the past few decades. Varieties of supported material were used to prepare the heterogeneous Pt catalysts, such as silica, ${ }^{14,15}$ mesostructured silica, ${ }^{16} \mathrm{Al}_{2} \mathrm{O}_{3},{ }^{17,18}$ glass fiber, ${ }^{19}$ polystyrene, ${ }^{20}$ polyethylene glycol$^{21}$ polyamide, ${ }^{22}$ carbon, ${ }^{23}$ graphene oxide ${ }^{24}$ and titania. ${ }^{25}$ Among these materials, silica is a theoretically good support material because it has high mechanical strength and high surface area and it is non-volatile, cheap and non-toxic. Besides, there are a large number of silicon hydroxyl groups on the surface of silica which can be easily modified with varieties of functional group such as 
sulfonate, phosphate, amine, etc., to increase the stability of the supported catalysts during the catalytic reaction.

polycarboxylic acids such as diethylenetriaminepentaacetic acid (DTPA), ethylenediaminetetraacetic acid (EDTA), nitrolotriacetic acid (NTA) and succinic acid (SA) are chelating agents and can form very stable chelates with metals. ${ }^{26}$ They were proved to efficiently complex to various metals. Almeida et al. ${ }^{27}$ prepared DTPA functionalized magnetic nanoparticles to separate $\mathrm{Nd}^{3+}$ and $\mathrm{La}^{3+}$ and achieved a high separation efficiency (>99\%). Shiraishi et al. ${ }^{28}$ used several inorganic adsorbents (silica gel, MCM-41, and aluminum oxide) modified by EDTA and DTPA as chelating ligands to absorb transition metals such as $\mathrm{Cu}^{2+}, \mathrm{Ni}^{2+}, \mathrm{VO}^{2+}, \mathrm{Zn}^{2+}, \mathrm{Co}^{2+}$ and $\mathrm{Mn}^{2+}$. Baraka et $a l .{ }^{29}$ synthesized a new chelating resin by anchoring NTA and used it to remove $\mathrm{Cu}^{2+}$ from synthetic wastewater. Ikodiya et $a{ }^{30}$ successfully removed $\mathrm{Ca}^{2+}$ from synthetic wastewater using SA modified red onion skin extract. Efforts in our laboratory have been directed towards creating EDTA-functionalized silica-supported Pt catalysts. $^{31}$ However, DTPA, NTA or SA functionalized silica gel have never been used as the support for Pt immobilization until this paper.

In this paper, to further extend our ongoing efforts towards the development of such polycarboxylic acid-functionalized $\mathrm{Pt}$ catalysts and to explore and compare their applications in alkene hydrosilylation, we report herein three novel polycarboxylic acid (including DTPA, NTA and SA)-functionalized silica gel supported Pt catalysts. The characteristics and catalytic ability of the three Pt catalysts were checked. Their catalytic activity and reusability were preliminarily evaluated using 1hexene hydrosilylation with methyldichlorosilane. Their catalytic efficiency and selectivity were further verified through catalyzing these hydrosilylation reactions between methyldichlorosilane and a series of linear alkenes (1-heptene, 1-octene, 1-decene, 1-do-decene, 1-tetra-decene, 1-hexa-decene, 1-octadecene, cis-hex-2-ene, styrene) and ring type alkenes (norbornene and cyclohexene).

\section{Experimental}

\subsection{Materials}

All commercially available solvents and reagents were analytical grade or better and were directly used without further purification unless otherwise stated. Silica gel was obtained from Yantai Xinnuo Chemical Industry Co., Ltd. (Shandong, China). Diethylenetriaminepentaacetic acid, nitrolotriacetic acid, 1hexene (99\%), 1-heptene (99\%), 1-hexa-decene (95\%) and 1octa-decene $(\geq 95 \%)$ were from Shanghai Macklin Biochemical Co., Ltd. (Shanghai, China). Butanedioic anhydride was from Tianjin Guangfu Fine Chemical Research Institute (Tianjin, China). 1-Octene (99\%) and norbornene (99\%) were from J\&K Scientific Ltd. (Beijing, China). 1-Do-decene (95\%) and 1-tetradecene (99\%) were from Meryer Chemical Technology Co., Ltd. (Shanghai, China). 1-Decene ( $\geq 95 \%)$ was from Adamas Reagent Co., Ltd. (Shanghai China). Dichloromethylhexylsilane (98\%) was from CNW Technologies Co., Ltd. (Nordrhein Westfalen, Germany). cis-2-Hexene was from Alfa Aesar Co., Ltd. (Massachusetts, USA). $\mathrm{H}_{2} \mathrm{PtCl}_{6} \cdot 6 \mathrm{H}_{2} \mathrm{O}$ and cyclohexene ( $\geq 98 \%$ ) were from Tianjin Kemat Chemical Technology Co., Ltd. (Tianjin, China). $\mathrm{CDCl}_{3}$ was from Energy Chemical Co., Ltd. (Shanghai, China). Other solvents were obtained from Tianjin Jiangtian Scientific Co., Ltd. (Tianjin, China).

\subsection{Instruments}

The immobilized Pt catalysts and other intermediates were characterized using infrared spectroscopy (IR, TENSOR 27, Bruker, Germany), transmission electron microscopy (TEM, JEM 2100F, JEOL Ltd., Japan), high-resolution transmission electron microscopy (HRTEM, JEM 2100F, JEOL Ltd., Japan), energy dispersive X-ray spectroscopy (EDS, X-Max, Oxford Instruments Ltd., Britain) and X-ray photoelectron spectroscopy (XPS, PHI-1600, PerkinElmer, US). Residual $\mathrm{H}_{2} \mathrm{PtCl}_{6}$ solutions were characterized using an ultraviolet-visible spectrophotometer (UV, U-3900, Hitachi, Japan). Pt loading was analyzed using an atomic absorption spectrophotometer (AAS, 180-80, Hitachi, Japan). The hydrosilylation products and diethylenetriaminepentaacetic dianhydride (DTPAD) were identified using a Bruker Advance $600 \mathrm{MHz}$ spectrometer (Bruker, Germany). The quantitative analysis of all hydrosilylation products were analyzed using GC with a capillary column $(30 \mathrm{~m} \times 0.25 \mathrm{~mm} \times$ $0.25 \mu \mathrm{m}$ ) coated with $5 \%$ phenyl and $95 \%$ methyl polysiloxane.

\subsection{Synthesis of Pt catalyst loaded on DTPA-functionalized silica gel ( $\mathrm{SiO}_{2}$-DTPA-Pt)}

2.3.1 Synthesis of DTPAD. DTPAD was synthesized according to the method reported previously by Tülü et $a .^{32}$ as shown in Fig. 1(B). Briefly, $23 \mathrm{~g}$ (0.06 mmol) DTPA was first dissolved in $30 \mathrm{ml}(0.36 \mathrm{mmol})$ anhydrous pyridine in a $100 \mathrm{ml}$ three-neck round flask with a straight condenser installed with a dry tube. Then, $23 \mathrm{ml}(0.24 \mathrm{~mol})$ acetic anhydride was added to the solution and the mixture was stirred vigorously at $65{ }^{\circ} \mathrm{C}$ for $24 \mathrm{~h}$. After cooling to room temperature, the product was separated by filtration and washed with diethyl ether three times. Then, the product was placed in a $250 \mathrm{ml}$ conical bottle and $58 \mathrm{ml}$ acetic anhydride was poured into it and the mixture was stirred for $30 \mathrm{~min}$ at room temperature in order to purify the DTPAD. The product was separated by vacuum filtration and washed three times with acetic anhydride and diethyl ether. After drying for $24 \mathrm{~h}$ at $60{ }^{\circ} \mathrm{C}$, the white product DTPAD was obtained.

2.3.2 Synthesis of DTPA-functionalized silica gel $\left(\mathrm{SiO}_{2}\right.$ DTPA). Silica gel was immersed in $6 \mathrm{M} \mathrm{HCl}$ at $60^{\circ} \mathrm{C}$ for $6 \mathrm{~h}$ and washed with distilled water until $\mathrm{pH}=7$. Then, the treated silica gel was separated by filtration and dried at $60{ }^{\circ} \mathrm{C}$ for $12 \mathrm{~h} .5 \mathrm{~g}$ treated silica gel was dried under vacuum for $3 \mathrm{~h}$ at $130{ }^{\circ} \mathrm{C}$ and placed in a $100 \mathrm{ml}$ 3-neck flask. Afterward, the aminofunctionalized silica gel was prepared by the dropwise addition of $7 \mathrm{ml} \gamma$-aminopropyltriethoxysilane (APTES) to $5 \mathrm{~g}$ silica gel in $50 \mathrm{ml}$ distilled toluene. Then, the reactants were stirred at $110^{\circ} \mathrm{C}$ for $24 \mathrm{~h}$, and collected by filtration, rinsed with acetone and toluene, and finally dried at $70{ }^{\circ} \mathrm{C}$ for $24 \mathrm{~h}$. To get DTPAfunctionalized silica gel, $2 \mathrm{~g}$ amino-functionalized silica gel and $6 \mathrm{~g}$ DTPAD were mixed and poured into a $100 \mathrm{ml}$ three-neck flask. Then, $36 \mathrm{ml}$ anhydrous ethanol and $36 \mathrm{ml}$ acetic acid were 


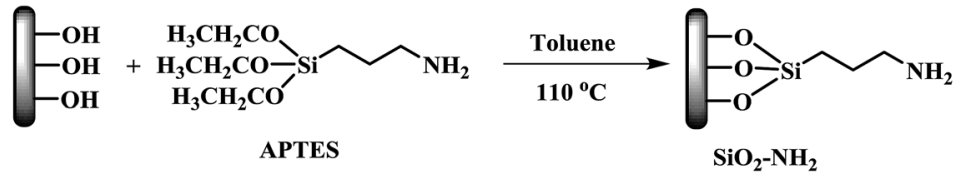

(A)

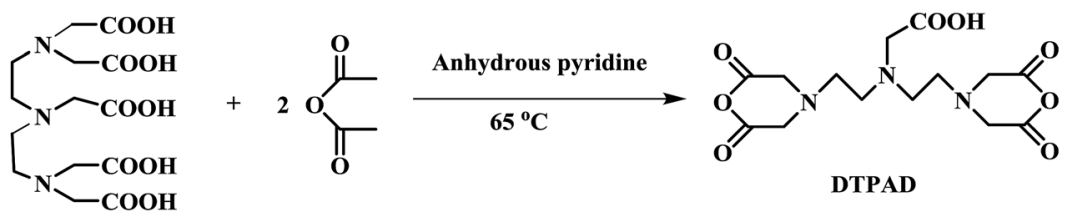

(B)

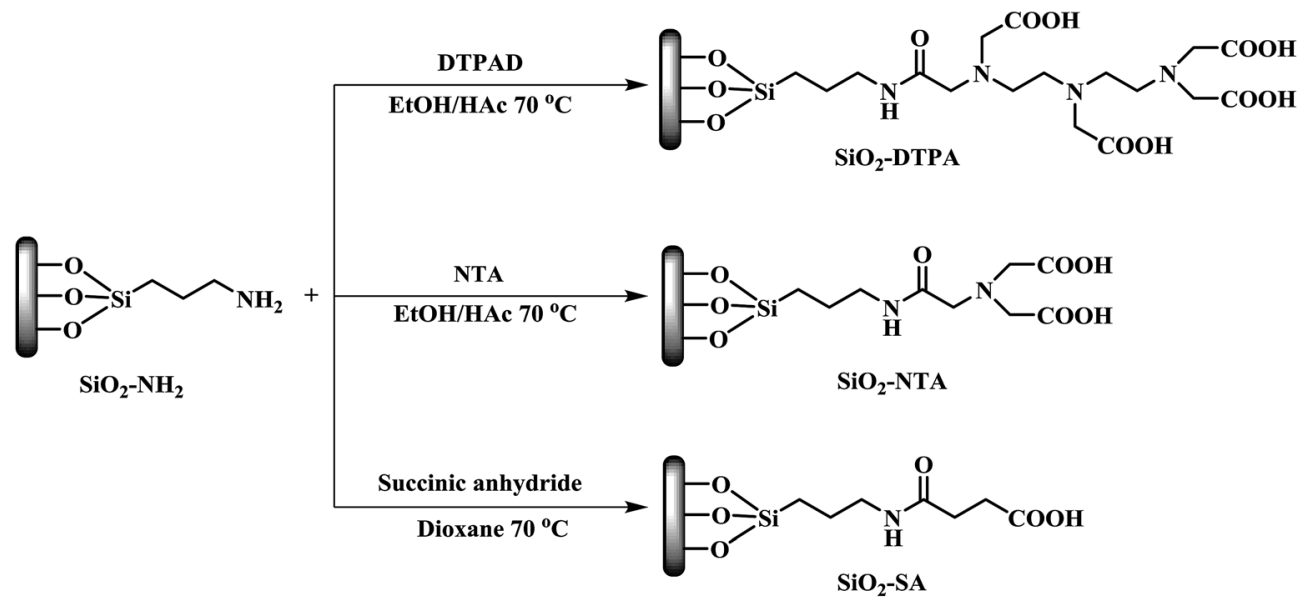

(C)

Fig. 1 A schematic illustration of (A) $\mathrm{SiO}_{2}-\mathrm{NH}_{2}$, (B) DTPAD, (C) polycarboxylic acid functionalized $\mathrm{SiO}_{2}$.

added into the mixture and stirred at $70{ }^{\circ} \mathrm{C}$ for $24 \mathrm{~h}$. After cooling to room temperature, the product was separated by filtration and washed with water and acetone and dried at $70{ }^{\circ} \mathrm{C}$ for $12 \mathrm{~h} .{ }^{33}$ The process is illustrated in Fig. 1(C), Step 1.

2.3.3 Synthesis of $\mathrm{SiO}_{2}$-DTPA-Pt. Firstly, $1 \mathrm{~g} \mathrm{H}_{2} \mathrm{PtCl}_{6} \cdot 6 \mathrm{H}_{2} \mathrm{O}$ was dissolved in $50 \mathrm{ml} i$-propanol to obtain $0.0386 \mathrm{~mol} \mathrm{l}^{-1}$ $\mathrm{H}_{2} \mathrm{PtCl}_{6}$ solution. Then, $0.8 \mathrm{~g} \mathrm{S_{0 }}$-DTPA and $80 \mathrm{ml}$ anhydrous ethanol was added into a $100 \mathrm{ml}$ 4-neck flask. Once the heating temperature reached $78{ }^{\circ} \mathrm{C}, 8 \mathrm{ml} i$-propanol- $\mathrm{H}_{2} \mathrm{PtCl}_{6}$ was added to the mixture and further heated to reflux at $78{ }^{\circ} \mathrm{C}$ under a continuous nitrogen flow for $9 \mathrm{~h}$. After cooling to room temperature, the yellow product was separated by filtration and washed with ethanol several times. Finally, the product was dried at $60{ }^{\circ} \mathrm{C}$ for $24 \mathrm{~h}$. The Pt catalyst was also prepared at different external temperatures $\left(30,50,70,90\right.$ and $\left.100{ }^{\circ} \mathrm{C}\right)$ with the corresponding internal temperature being 25, 43, 62, 75 and $78{ }^{\circ} \mathrm{C}$, respectively. The $\mathrm{SiO}_{2}$-DTPA-Pt was prepared in different solvents including ethanol, $i$-propanol, $n$-butanol and $n$-hexanol at $78{ }^{\circ} \mathrm{C}$.

\subsection{Synthesis of Pt catalyst loaded on NTA-functionalized silica gel ( $\mathrm{SiO}_{2}$-NTA-Pt)}

To obtain NTA-functionalized silica gel, $10 \mathrm{~g}$ NTA and $8 \mathrm{~g}$ amino-functionalized silica gel, as prepared in Section 2.3.2, were mixed and added to a $250 \mathrm{ml}$ three-neck flask. Then, $80 \mathrm{ml}$ anhydrous ethanol and $80 \mathrm{ml}$ acetic acid were poured into the mixture and mechanically stirred at $70{ }^{\circ} \mathrm{C}$ for $24 \mathrm{~h}$. After cooling to room temperature, the product was separated by filtration and rinsed with water and acetone and dried at $70{ }^{\circ} \mathrm{C}$ for $12 \mathrm{~h}$. The synthetic process is illustrated in Fig. 1(C) Step 2. To get

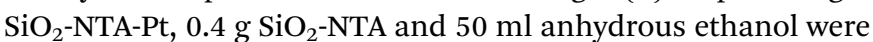
added into a $100 \mathrm{ml}$ 4-neck flask. Once the heating temperature reached $78{ }^{\circ} \mathrm{C}, 4 \mathrm{ml} i$-propanol- $\mathrm{H}_{2} \mathrm{PtCl}_{6}\left(0.0386 \mathrm{~mol} \mathrm{l}^{-1}\right)$ was added to the mixture and further heated to reflux at $78{ }^{\circ} \mathrm{C}$ under a continuous nitrogen flow for $9 \mathrm{~h}$. After cooling to room temperature, the yellow product was separated by filtration and washed with ethanol several times. Finally, the product was dried at $60{ }^{\circ} \mathrm{C}$ for $24 \mathrm{~h}$.

\subsection{Synthesis of Pt catalyst loaded on SA-functionalized} silica gel $\left(\mathrm{SiO}_{2}-\mathrm{SA}-\mathrm{Pt}\right)$

Fig. 1(C) step 3 shows the preparation process of SAfunctionalized silica gel. A total of $6 \mathrm{~g}$ butanedioic anhydride, $6 \mathrm{~g}$ amino-functionalized silica gel as prepared in Section 2.3.2 and $100 \mathrm{ml}$ dioxane were added into a $250 \mathrm{ml}$ 3-neck flask. The mixture was stirred at $70{ }^{\circ} \mathrm{C}$ for $24 \mathrm{~h}$. The product was separated by filtration and rinsed with acetone and water several times. Finally, the SA-functionalized silica gel was dried at $70{ }^{\circ} \mathrm{C}$ for 


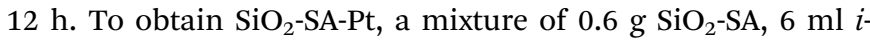
propanol- $\mathrm{H}_{2} \mathrm{PtCl}_{6}$ solution $\left(0.0386 \mathrm{~mol} \mathrm{l}^{-1}\right)$ and $60 \mathrm{ml}$ anhydrous ethanol was stirred at $78^{\circ} \mathrm{C}$ for $9 \mathrm{~h}$. Then, the product was separated by filtration and washed with ethanol several times and dried at $60{ }^{\circ} \mathrm{C}$ for $24 \mathrm{~h}$.

\subsection{Evaluation and application of the immobilized Pt catalysts}

Firstly, 1-hexene hydrosilylation with methyldichlorosilane was used to evaluate the catalytic activities of $\mathrm{SiO}_{2}$-DTPA-Pt, $\mathrm{SiO}_{2}$ NTA-Pt and $\mathrm{SiO}_{2}$-SA-Pt. The alkane hydrosilylation was tested in a $50 \mathrm{ml}$ conical centrifuge tube which was equipped with a condenser at the top of the tube to avoid evaporation of the solution. Typically, for $\mathrm{SiO}_{2}$-DTPA-Pt, an appropriate amount of Pt catalyst loaded on DTPA-functionalized silica gel containing $2.8 \times 10^{-3} \mathrm{mmol} \mathrm{Pt}$ was added to the $50 \mathrm{ml}$ conical centrifuge tube with a magnetic stirrer. Then, an appropriate amount of 1hexene $(10 \mathrm{mmol})$ was added to the system and the reactants were stirred at $60{ }^{\circ} \mathrm{C}$ for $30 \mathrm{~min}$. Afterward, an appropriate amount of methyldichlorosilane $(18 \mathrm{mmol})$ was added to the system. The reaction mixture was heated to $60{ }^{\circ} \mathrm{C}$ and magnetically stirred for $4 \mathrm{~h}$ and after cooling down to room temperature, the reaction mixture was separated by centrifugation. $\mathrm{SiO}_{2}$-NTA-Pt $\left(2.3 \times 10^{-3} \mathrm{mmol} \mathrm{Pt}\right)$ and $\mathrm{SiO}_{2}$-SA-Pt $(2.9 \times$ $10^{-3} \mathrm{mmol} \mathrm{Pt}$ ) were used to catalyze the model reaction and the experimental conditions and procedures were the same as for the catalytic reaction using $\mathrm{SiO}_{2}$-DTPA-Pt. The reactants were filtrated with a $0.22 \mu \mathrm{m}$ microporous filter before quantitative analysis with GC. ${ }^{1} \mathrm{H}$ NMR spectra were recorded on a Bruker AC-P400 (600 MHz) spectrometer to characterize the structure of the product.

In addition, a series of linear alkenes and ring type alkenes were chosen to evaluate and compare the catalytic activity, selectivity and feasibility of the $\mathrm{SiO}_{2}$-DTPA-Pt, $\mathrm{SiO}_{2}$-NTA-Pt and $\mathrm{SiO}_{2}$-SA-Pt catalysts. Hydrosilylation reactions between different olefins and methyldichlorosilane were also carried out in a $50 \mathrm{ml}$ conical centrifuge tube which was equipped with a condenser at the top of the tube to avoid evaporation of the solution and a magnetic stirrer. Typical reaction conditions

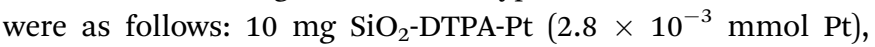

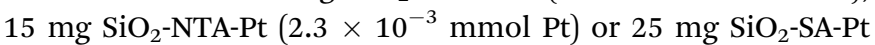
$\left(2.9 \times 10^{-3} \mathrm{mmol} \mathrm{Pt}\right)$ was added to $10 \mathrm{mmol}$ short-chained olefins (1-heptene, 1-octene, styrene, norbornene or cyclohexene), $5.0 \mathrm{mmol}$ olefins (cis-hex-2-ene) or $5.0 \mathrm{mmol}$ longchained alkenes (1-decene, 1-do-decene, 1-tetra-decene, 1hexa-decene, or 1-octa-decene). The mixture was stirred at $60{ }^{\circ} \mathrm{C}$ for $30 \mathrm{~min}$. Afterward, an appropriate amount of methyldichlorosilane (18 $\mathrm{mmol}$ ) was added to the mixture. The reactants were heated to $60{ }^{\circ} \mathrm{C}$ and magnetically stirred for $5 \mathrm{~h}$ for longchained alkenes or $4 \mathrm{~h}$ for other olefins and after cooling down to room temperature, the mixture was separated by centrifugation.

In reusability experiments, 1-hexene hydrosilylation with methyldichlorosilane was used to evaluate the reusability of $\mathrm{SiO}_{2}$-DTPA-Pt, $\mathrm{SiO}_{2}$-NTA-Pt and $\mathrm{SiO}_{2}$-SA-Pt. After each catalytic reaction for these three Pt catalysts, the reactants could be separated from the system by centrifugation. Then, the heterogeneous Pt catalysts could be held in the original system and reused for the next catalytic reaction without any other processes.

\subsection{Characterization of the immobilized Pt catalysts}

The intermediates and immobilized platinum catalysts, DTPAD, $\mathrm{SiO}_{2}, \mathrm{SiO}_{2}-\mathrm{NH}_{2}, \mathrm{SiO}_{2}$-DTPA, $\mathrm{SiO}_{2}-\mathrm{NTA}, \mathrm{SiO}_{2}-\mathrm{SA}, \mathrm{SiO}_{2}-$ DTPA-Pt, $\mathrm{SiO}_{2}$-NTA-Pt and $\mathrm{SiO}_{2}$-SA-Pt were characterized using IR. DTPAD was also identified using ${ }^{1} \mathrm{H}$ NMR. The elemental distributions of the catalysts $\left(\mathrm{SiO}_{2}\right.$-DTPA-Pt, $\mathrm{SiO}_{2}$-NTA-Pt and $\mathrm{SiO}_{2}$-SA-Pt) were analyzed using EDS. The size, morphology and distribution of the catalyst particles were observed using TEM and HRTEM. The samples were prepared by dispersing them in deionized water on a Formvar/carbon film coated $\mathrm{Cu}$ grid, followed by drying under ambient conditions. The binding energies of Pt from the catalysts were characterized using XPS. The actual Pt loadings for all the catalysts were determined using AAS. The $\mathrm{H}_{2} \mathrm{PtCl}_{6}$ residual liquid after immobilization was determined using UV spectrometry at wavelengths from $220 \mathrm{~nm}$ to $500 \mathrm{~nm}$ to investigate the change in valence state of the Pt. The ${ }^{1} \mathrm{H}$ NMR spectra were recorded on a Bruker AC-P400 (600 $\mathrm{MHz})$ spectrometer to characterize the structure of the products. The yield of the products of the reactions between alkenes and methyldichlorosilane were determined using GC. The GC conditions for short-chained alkenes were as follows: the split ratio was $30: 1$; the sampling volume was $0.8 \mu \mathrm{l}$; the column temperature was increased from $60{ }^{\circ} \mathrm{C}$ to $260{ }^{\circ} \mathrm{C}$ at a rate of $10{ }^{\circ} \mathrm{C} \mathrm{min}{ }^{-1}$; the time duration for the highest temperature was $5 \mathrm{~min}$; the temperature of injection and detection was $260{ }^{\circ} \mathrm{C}$. The GC conditions of the reactions between long-chained alkenes (1-decene, 1-do-decene, 1-tetra-decene, 1-hexa-decene, or 1-octa-decene) and methyldichlorosilane were as follows: the column temperature was increased from $60{ }^{\circ} \mathrm{C}$ to $280{ }^{\circ} \mathrm{C}$ at a rate of $10{ }^{\circ} \mathrm{C} \min ^{-1}$; the duration time for the highest temperature was $5 \mathrm{~min}$; the temperature of injection and detection was $280{ }^{\circ} \mathrm{C}$; the sampling volume was $0.6 \mu \mathrm{l}$.

\section{Results and discussion}

\subsection{Characterization of the catalysts}

3.1.1 IR and NMR analysis of DTPAD. The IR spectrum of DTPAD is shown in Fig. S1(A). $\dagger$ The absorption bands at $1816 \mathrm{~cm}^{-1}$ and $1770 \mathrm{~cm}^{-1}$ can be ascribed to the characteristic bands of anhydride. The absorption at $1641 \mathrm{~cm}^{-1}, 2821 \mathrm{~cm}^{-1}$ and $2982 \mathrm{~cm}^{-1}$ originate from the vibration bands of $\mathrm{C}=\mathrm{O}$ and $\mathrm{O}-\mathrm{H}$ of the carboxyl group, respectively. In addition, there are absorption bands at $1366 \mathrm{~cm}^{-1}, 1335 \mathrm{~cm}^{-1}$ and $1111 \mathrm{~cm}^{-1}$, corresponding to the vibration absorption of the $\mathrm{C}-\mathrm{N}$ group, and the peaks at $1298-1204 \mathrm{~cm}^{-1}$ are related to $\mathrm{C}-\mathrm{O}$ stretching. ${ }^{34}{ }^{1} \mathrm{H}$ NMR (DMSO, $600 \mathrm{MHz}$ ) is shown in Fig. S1(B) $\dagger$ and these NMR data are consistent with the characteristic peaks of DTPAD. ${ }^{35}$

3.1.2 IR analysis of the Pt catalysts. Comparisons of the FTIR spectra of $\mathrm{SiO}_{2}, \mathrm{SiO}_{2}-\mathrm{NH}_{2}, \mathrm{SiO}_{2}$-DTPA, $\mathrm{SiO}_{2}-\mathrm{NTA}, \mathrm{SiO}_{2}-\mathrm{SA}$, $\mathrm{SiO}_{2}$-DTPA-Pt, $\mathrm{SiO}_{2}$-NTA-Pt and $\mathrm{SiO}_{2}$-SA-Pt are shown in 


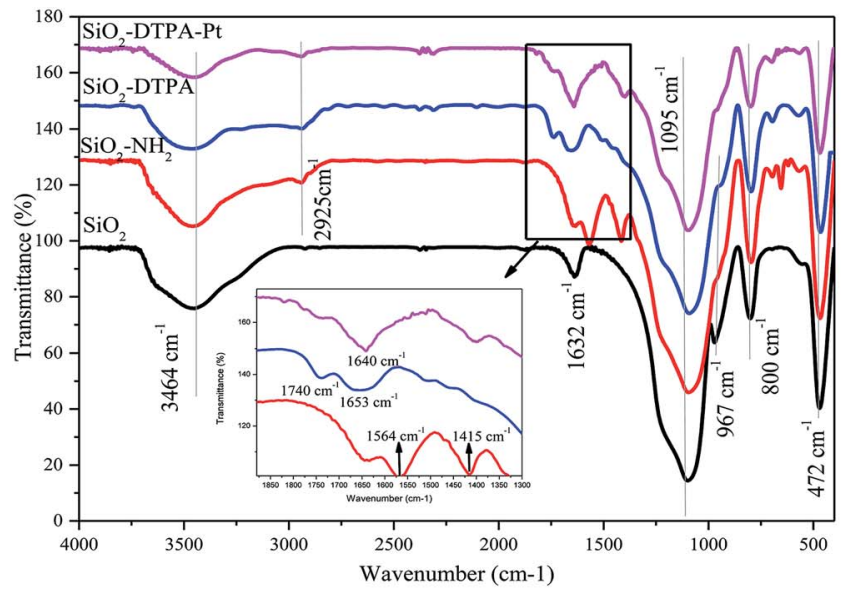

(A)

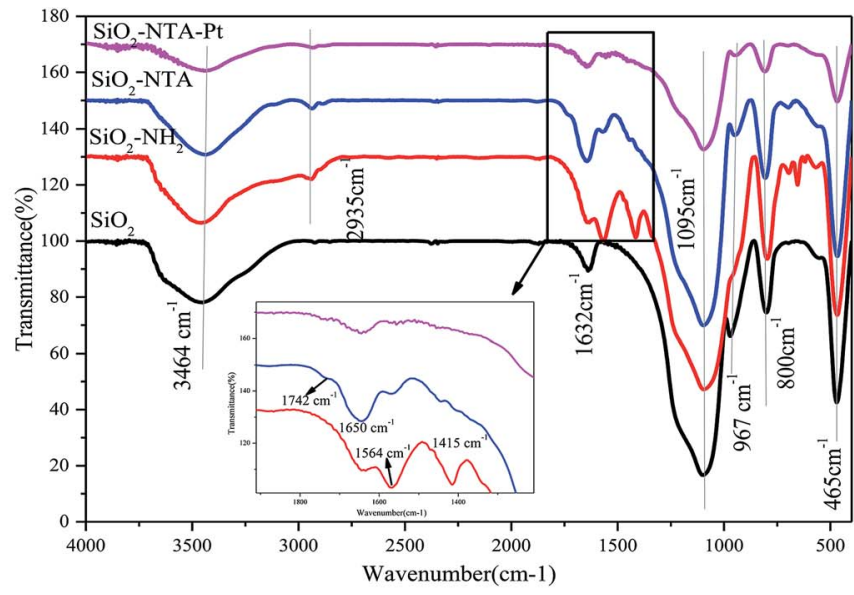

(B)

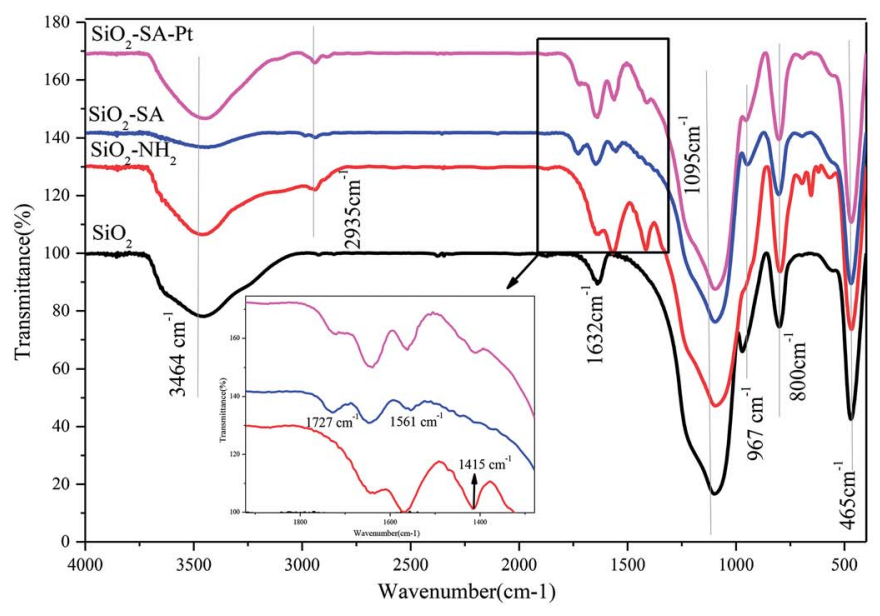

(C)

Fig. 2 IR spectra of (A) silica gel, $\mathrm{SiO}_{2}-\mathrm{NH}_{2}, \mathrm{SiO}_{2}-\mathrm{DTPA}$ and $\mathrm{SiO}_{2}-\mathrm{DTPA}-\mathrm{Pt}$, (B) silica gel, $\mathrm{SiO}_{2}-\mathrm{NH}_{2}, \mathrm{SiO}_{2}-\mathrm{NTA}$ and $\mathrm{SiO} 2-\mathrm{NTA}-\mathrm{Pt}$ and (C) $\mathrm{SiO} \mathrm{O}_{2}-$ $\mathrm{NH}_{2}, \mathrm{SiO}_{2}-\mathrm{SA}$ and $\mathrm{SiO}_{2}-\mathrm{SA}-\mathrm{Pt}$.

Fig. 2(A-C). In the $\mathrm{SiO}_{2}$ spectrum, the large, broad and intense bands at $1095 \mathrm{~cm}^{-1}$ and $800 \mathrm{~cm}^{-1}$ correspond to $\mathrm{Si}-\mathrm{O}-\mathrm{Si}$ stretching, the peak at $472 \mathrm{~cm}^{-1}$ corresponds to $\mathrm{Si}-\mathrm{O}-\mathrm{Si}$ bending and the peak at $967 \mathrm{~cm}^{-1}$ arises from $\mathrm{Si}-\mathrm{OH}$ bending (observed in all samples). Another two peaks at $1632 \mathrm{~cm}^{-1}$ and $3464 \mathrm{~cm}^{-1}$ correspond to isolated hydroxyl groups on the silica surface. ${ }^{36}$ In the $\mathrm{SiO}_{2}-\mathrm{NH}_{2}$ spectrum, new peaks appear at $2925 \mathrm{~cm}^{-1}$ and $1415 \mathrm{~cm}^{-1}$ corresponding to $-\mathrm{CH}_{2}-$ stretching and bending vibrations of the pendant propyl chain and the band at $1564 \mathrm{~cm}^{-1}$ is from $-\mathrm{NH}_{2}$ - vibrations. ${ }^{14}$ For $\mathrm{SiO}_{2}$-DTPA, $\mathrm{SiO}_{2}$-NTA, and $\mathrm{SiO}_{2}$-SA, the two peaks at $1740 \mathrm{~cm}^{-1}$ and $1653 \mathrm{~cm}^{-1}$ ( $\mathrm{SiO}_{2}$-DTPA), $1742 \mathrm{~cm}^{-1}$ and $1650 \mathrm{~cm}^{-1}$ for $\mathrm{SiO}_{2}$-NTA and $1727 \mathrm{~cm}^{-1}$ and $1647 \mathrm{~cm}^{-1}$ for $\mathrm{SiO}_{2}$-SA are from carbonyl groups. The disappearance of carbonyl groups at $1740 \mathrm{~cm}^{-1}$ in $\mathrm{SiO}_{2}$-DTPA-Pt, $1742 \mathrm{~cm}^{-1}$ in $\mathrm{SiO}_{2}$-NTA-Pt and $1727 \mathrm{~cm}^{-1}$ in $\mathrm{SiO}_{2}-$ SA-Pt indicates that Pt successfully anchors to the modified silica gel through carbonyl groups.

3.1.3 TEM and EDS analysis of the Pt catalysts. The TEM images of $\mathrm{SiO}_{2}$-DTPA-Pt, $\mathrm{SiO}_{2}$-NTA-Pt and $\mathrm{SiO}_{2}$-SA-Pt are presented in Fig. 3(A-C), where the dark spots on the surface of the catalysts could be Pt and the morphology and distribution of Pt could be observed. Characteristic patterns of Pt (111) planes $(d=0.227 \mathrm{~nm})$ were also observed. Highly dispersed Pt particles were detected in the TEM images of $\mathrm{SiO}_{2}$-DTPA-Pt and the size of the Pt particles was about 3-4 $\mathrm{nm}$, and they had better dispersion than in $\mathrm{SiO}_{2}$-NTA-Pt and $\mathrm{SiO}_{2}$-SA-Pt. Some aggregated particles larger than $5 \mathrm{~nm}$ were detected in the TEM images of $\mathrm{SiO}_{2}$-NTA-Pt and $\mathrm{SiO}_{2}$-SA-Pt. These results indicate that the DTPA functionalized silica could be used as an efficient support for forming highly dispersed, ultra small sized Pt particles. As shown in Fig. 3(D-F), the EDS analysis revealed the presence of $\mathrm{Pt}$ and the corresponding elements of $\mathrm{C}, \mathrm{O}, \mathrm{N}, \mathrm{Si}$ and $\mathrm{Cl}$ in all of the catalysts $\left(\mathrm{SiO}_{2}\right.$-DTPA-Pt, $\mathrm{SiO}_{2}$-NTA-Pt and $\mathrm{SiO}_{2}$-SA-Pt). Before the EDS determination, the samples need to be coated on the $\mathrm{Cu}$ grid of a formavar/carbon film. This is the reason for $\mathrm{Cu}$ in the $\mathrm{X}$-ray spectra.

3.1.4 Analysis of Pt valence states for the Pt catalysts. To explore the valence state change of $\mathrm{Pt}$ on immobilization on $\mathrm{SiO}_{2}$-DTPA, $\mathrm{SiO}_{2}$-NTA and $\mathrm{SiO}_{2}$-SA, the residual $\mathrm{H}_{2} \mathrm{PtCl}_{6}$ solutions were analyzed using $\mathrm{UV}$ and the data are shown in 

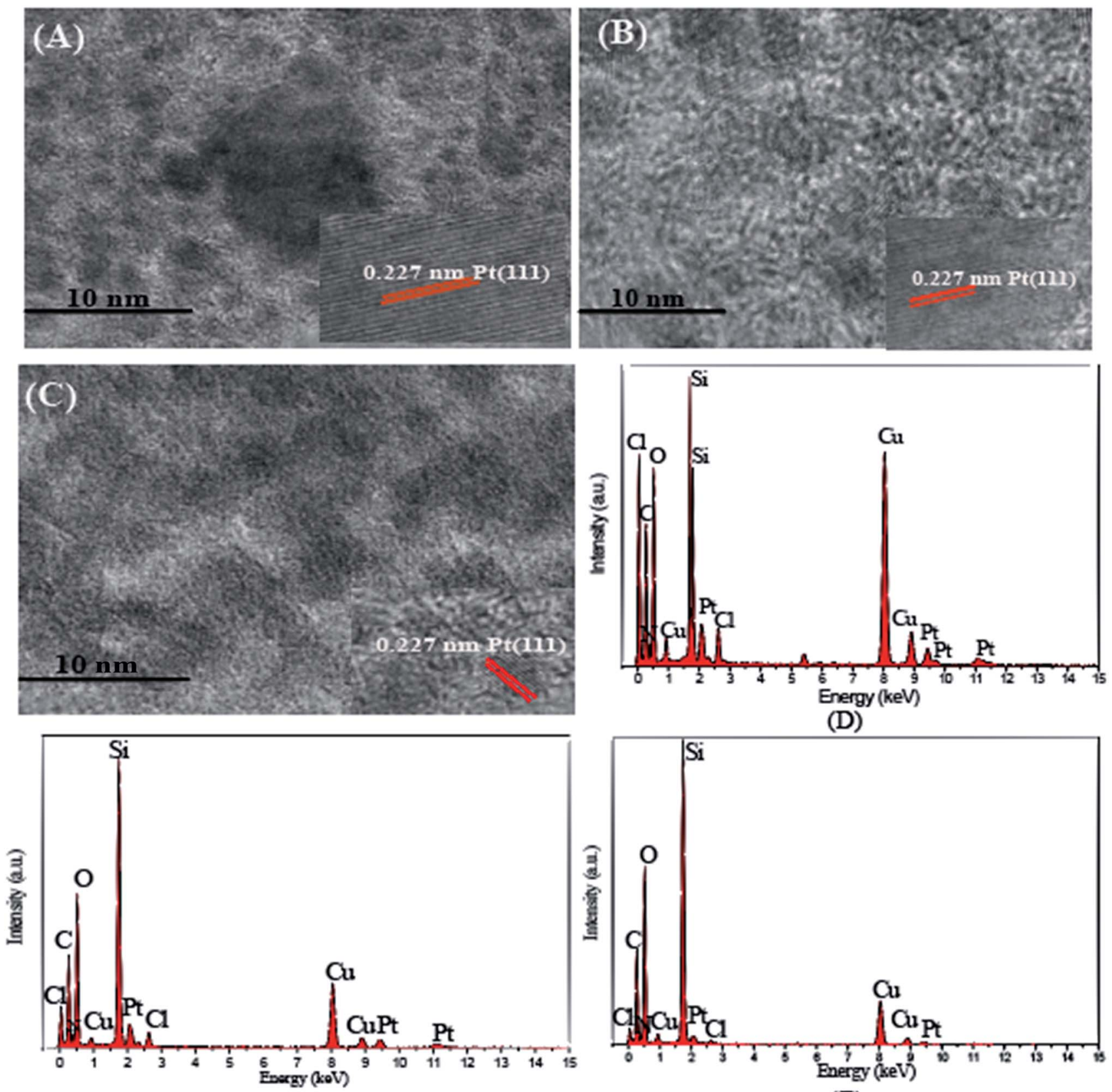

(E)

(F)

Fig. 3 The TEM images of (A) $\mathrm{SiO}_{2}-$ DTPA-Pt, (B) $\mathrm{SiO}_{2}-\mathrm{NTA}-\mathrm{Pt}$ and (C) $\mathrm{SiO}_{2}-\mathrm{SA}-\mathrm{Pt}$; the EDS spectra of (D) SiO - DTPA-Pt, (E) SiO $2-\mathrm{NTA}-\mathrm{Pt}$, and (F) $\mathrm{SiO}_{2}-\mathrm{SA}-\mathrm{Pt}$.

Fig. S2(A-D). $\dagger$ The results indicate that their maximum absorbance was quite different from the primary absorbance. The absorbance of the original $\mathrm{H}_{2} \mathrm{PtCl}_{6}$ solution appears at $265 \mathrm{~nm}$ (Fig. S2(A) $\dagger$ ) and is consistent with the absorbance of Pt(Iv) reported before. ${ }^{37}$ The absorbance at $265 \mathrm{~nm}$ for the residual $\mathrm{Pt}$ decreased to $243 \mathrm{~nm}$ for $\mathrm{SiO}_{2}$-DTPA-Pt and $\mathrm{SiO}_{2}$-NTA-Pt (Fig. S2(B and C) $\dagger$ ) and decreased to $242 \mathrm{~nm}$ for $\mathrm{SiO}_{2}-\mathrm{SA}-\mathrm{Pt}$ (Fig. S2(D) $\dagger$ ), which is consistent with the absorbance of Pt particles reported before. ${ }^{21}$ The changes confirm that Pt has been successfully immobilized on the APCA-functionalized silica gel with other forms.
3.1.5 XPS and AAS analysis of the Pt catalysts. XPS was employed to obtain surface information on Pt oxidation states and compositions of the $\mathrm{SiO}_{2}$-DTPA-Pt, $\mathrm{SiO}_{2}$-NTA-Pt, and $\mathrm{SiO}_{2}$ SA-Pt catalysts. As shown in Fig. 4 (A), the spectra also indicate the presence of $\mathrm{O}, \mathrm{C}, \mathrm{N}, \mathrm{Si}, \mathrm{Cl}$ and $\mathrm{Pt}$ for $\mathrm{SiO}_{2}$-DTPA-Pt, $\mathrm{SiO}_{2}$ NTA-Pt, and $\mathrm{SiO}_{2}$-SA-Pt, which is in agreement with the EDS data. The results of the elemental analysis of these three Pt catalysts are shown in Table 1 . The C content was $32.6 \%, 30.4 \%$ and $24.6 \%$, while the $\mathrm{N}$ content was $5.6 \%, 4.2 \%$ and $3.6 \%$ for $\mathrm{SiO}_{2}$-DTPA-Pt, $\mathrm{SiO}_{2}$-NTA-Pt, and $\mathrm{SiO}_{2}$-SA-Pt respectively. Fig. 4(B-D) shows the Pt 4 f spectra of $\mathrm{SiO}_{2}$-DTPA-Pt, $\mathrm{SiO}_{2}-\mathrm{NTA}-\mathrm{Pt}$ 
and $\mathrm{SiO}_{2}$-SA-Pt. Deconvolution of the $\mathrm{Pt} 4 \mathrm{f}$ region shows the presence of two pairs of doublets. The most intense doublet with binding energies of $71.6\left(\mathrm{Pt}_{4 \mathrm{f}_{7 / 2}}\right)$ and $74.8 \mathrm{eV}\left(\mathrm{Pt}_{4 \mathrm{f}_{5 / 2}}\right)$ was attributed to metallic Pt. ${ }^{38}$ Peaks at $72.9\left(\mathrm{Pt} 4 \mathrm{f}_{7 / 2}\right)$ and $76.4 \mathrm{eV}(\mathrm{Pt}$ $4 \mathrm{f}_{5 / 2}$ ) could be assigned to $\mathrm{Pt}^{\delta+}$. The amount of metallic Pt was $63.6 \%$ in $\mathrm{SiO}_{2}$-DTPA-Pt, which was higher than that of $\mathrm{SiO}_{2}$ NTA-Pt (59.8\%) and $\mathrm{SiO}_{2}$-SA-Pt (54.9). These results could be attributed to the fact that DTPA has a stronger charge binding ability than NTA or $\mathrm{SA}^{39}$ and more $\mathrm{C}$ and $\mathrm{N}$ exists in DTPA functionalized silica. The formation of metallic Pt might be caused by the interaction of the polycarboxylic acid with Pt. ${ }^{40}$

The actual Pt loadings for the polycarboxylic acidfunctionalized silica supported Pt catalysts were determined using AAS. The data shows that the Pt loading for $\mathrm{SiO}_{2}$-DTPA-Pt was $0.287 \mathrm{mmol} \mathrm{g}^{-1}$ or $5.59 \mathrm{wt} \%$, which was higher than that of
Table 1 Elemental analysis of Pt catalysts by XPS

\begin{tabular}{|c|c|c|c|c|c|c|}
\hline \multirow[b]{2}{*}{ Catalyst } & \multicolumn{4}{|c|}{ Mass concentration (\%) } & \multicolumn{2}{|c|}{$\begin{array}{l}\text { Relative atomic } \\
\text { percentage }(\%)\end{array}$} \\
\hline & C 1s & $\mathrm{N} 1 \mathrm{~s}$ & O 1s & Pt $4 f$ & Metallic Pt & $\mathrm{Pt}^{\delta+}$ \\
\hline $\mathrm{SiO}_{2}$-DTPA-Pt & 32.6 & 5.6 & 41.6 & 1 & 63.64 & 36.36 \\
\hline $\mathrm{SiO}_{2}$-NTA-Pt & 30.4 & 4.2 & 44.4 & 0.9 & 59.83 & 40.17 \\
\hline $\mathrm{SiO}_{2}-\mathrm{SA}-\mathrm{Pt}$ & 24.6 & 3.6 & 50.5 & 0.5 & 54.86 & 45.14 \\
\hline
\end{tabular}

$3.84 \mathrm{wt} \%$ for $\mathrm{SiO}_{2}$-EDTA-Pt, ${ }^{31} 2.93 \mathrm{wt} \%$ for $\mathrm{SiO}_{2}$-NTA-Pt, and $2.30 \mathrm{wt} \%$ for $\mathrm{SiO}_{2}$-SA-Pt. The amount of $\mathrm{Pt}$ in these APCAfunctionalized silica supported Pt catalysts follows the order: $\mathrm{SiO}_{2}$-DTPA-Pt $>\mathrm{SiO}_{2}$-EDTA-Pt $>\mathrm{SiO}_{2}$-NTA-Pt $>\mathrm{SiO}_{2}$-SA-Pt. These

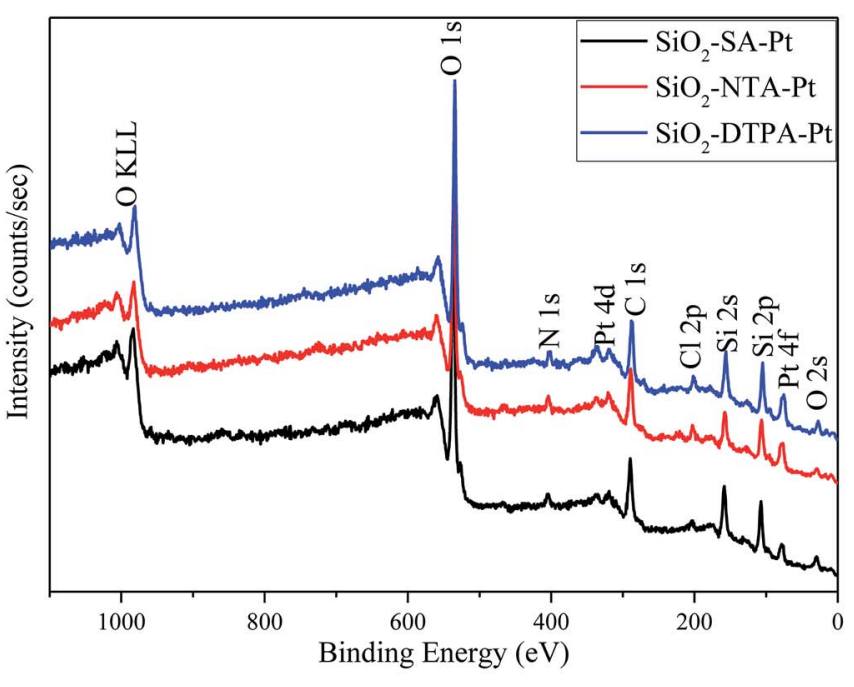

(A)

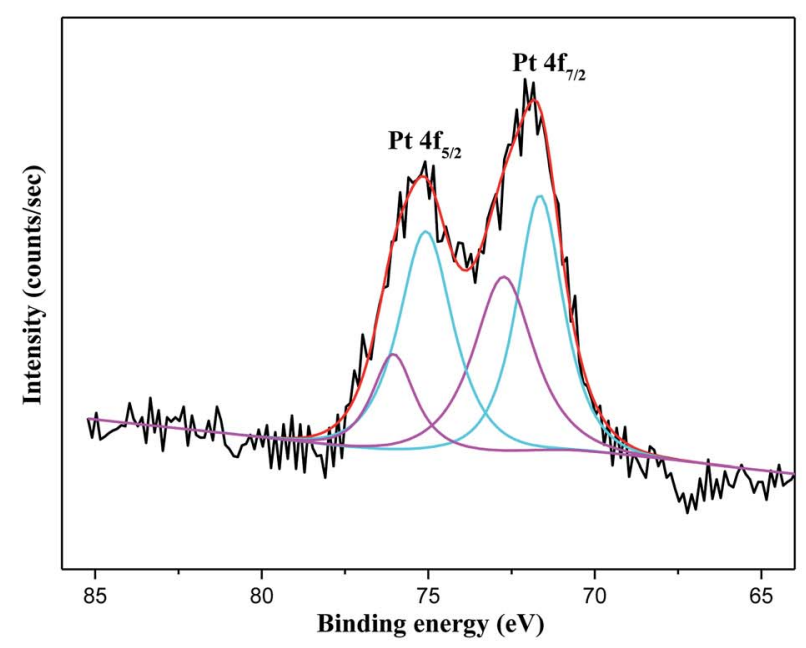

(C)

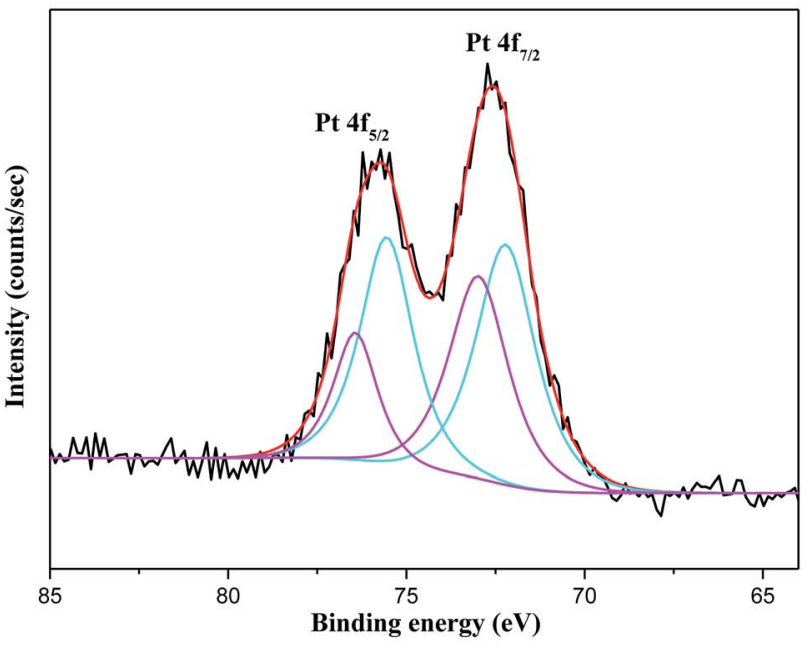

(B)

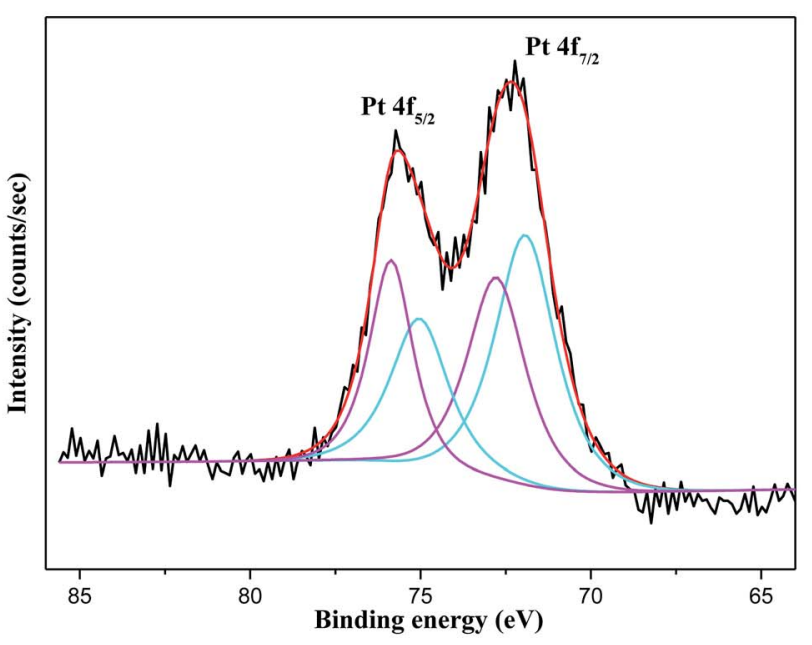

(D)

Fig. 4 XPS spectra of $\mathrm{SiO}_{2}-\mathrm{DTPA}-\mathrm{Pt}, \mathrm{SiO}_{2}-\mathrm{NTA}-\mathrm{Pt}$, and $\mathrm{SiO}_{2}-\mathrm{SA}-\mathrm{Pt}(\mathrm{A})$, XPS Pt 4 f spectra of $\mathrm{SiO}_{2}-\mathrm{DTPA}-\mathrm{Pt}(\mathrm{B}), \mathrm{SiO}_{2}-\mathrm{NTA}-\mathrm{Pt}(\mathrm{C})$, and $\mathrm{SiO} \mathrm{O}_{2}-\mathrm{SA}-\mathrm{Pt}$ (D). 
results indicate that DTPA could help to immobilize more Pt on the modified silica gel.

\subsection{Catalytic properties of the Pt catalysts}

3.2.1 Catalytic activity of immobilized Pt catalysts. Herein, 1-hexene hydrosilylation with methyldichlorosilane was used to evaluate the catalytic properties of $\mathrm{SiO}_{2}$-DTPA-Pt, $\mathrm{SiO}_{2}-\mathrm{NTA}-\mathrm{Pt}$ and $\mathrm{SiO}_{2}$-SA-Pt (all of these catalysts were prepared at $80{ }^{\circ} \mathrm{C}$ in anhydrous ethanol). The results are shown in Fig. S5 $\dagger$ and Table 2 . In the GC chromatograms shown in Fig. S5A, $\uparrow$ only one product peak around 11.92 min was observed and its retention time is consistent with that of 1-dichloromethylhexylsilane. The data of its ${ }^{1} \mathrm{H}$-NMR spectrum (see Fig. S5B $\dagger$ ) verified that the reaction product was dichloromethylhexylsilane and that the three immobilized Pt catalysts have good selectivity for the hydrosilylation of 1-hexene and methyldichlorosilane. $\mathrm{SiO}_{2}$ DTPA-Pt showed the highest activity, achieving the desired product in a $99.6 \%$ yield with a $1.79 \mathrm{~s}^{-1} \mathrm{TOF}$, and $\mathrm{SiO}_{2}-\mathrm{NTA}-\mathrm{Pt}$ also showed high activity, achieving 1-hexyl-methyldichlorosilane in a $94.4 \%$ yield with a $1.27 \mathrm{~s}^{-1}$ TOF. Meanwhile, the yield of 1-hexyl-methyl-dichlorosilane catalyzed by $\mathrm{SiO}_{2}$-SA-Pt was $97.1 \%$ with a lower TOF $\left(0.14 \mathrm{~s}^{-1}\right)$. This data indicates that the three immobilized Pt catalysts have high activity for the hydrosilylation of 1-hexene and methyldichlorosilane under optimal conditions. However, the variation trend of these three catalysts represented by the TOF was different. $\mathrm{SiO}_{2}$-SA-Pt showed the lowest TOF with a product yield that was only $33.8 \%$ after a $2 \mathrm{~h}$ reaction while the yield of dichloromethylhexylsilane was $95.9 \%$ for $\mathrm{SiO}_{2}$-DTPA-Pt or $88.8 \%$ for $\mathrm{SiO}_{2}$-NTA-Pt. These results demonstrate that the constituent of the polycarboxylic acid group plays a critical role in the hydrosilylation of 1-hexene and methyldichlorosilane.

3.2.2 Optimization and evaluation of the preparation conditions for $\mathrm{SiO}_{2}$-DTPA-Pt. The catalytic activity of EDTAfunctionalized silica supported Pt or $\mathrm{Al}_{2} \mathrm{O}_{3}$-supported Pt catalysts could be strongly affected by their preparation conditions. ${ }^{18,31}$ Therefore, the influence of the preparation conditions (temperature and solvents) were investigated for $\mathrm{SiO}_{2}$-DTPA-Pt.

The Pt catalyst was prepared as in Section 2.3.3 at different external temperatures $\left(30,50,70,90\right.$ or $\left.100{ }^{\circ} \mathrm{C}\right)$ with the corresponding internal temperatures being $25,43,62,75$ and $78{ }^{\circ} \mathrm{C}$, respectively. The results (Table 3 ) reveal that the preparation temperature has a vital influence on the catalytic activity of $\mathrm{SiO}_{2}$-DTPA-Pt. The yield of the product increased and the inductive period shortened with increasing preparation temperature for $\mathrm{SiO}_{2}$-DTPA-Pt. When the preparation temperature was lower than the boiling point of ethanol $\left(78^{\circ} \mathrm{C}\right)$, the $\mathrm{Pt}$ loading on $\mathrm{SiO}_{2}$-DTPA-Pt increased from $0.128 \mathrm{mmol} \mathrm{g}^{-1}$ to $0.231 \mathrm{mmol} \mathrm{g}^{-1}$ as the temperature increased, and the yield increased from $88.0 \%$ to $95.3 \%$ after $4 \mathrm{~h}$. Meanwhile, the yield increased to the maximum (99.6\%) as the preparation temperature increased to $78{ }^{\circ} \mathrm{C}\left(0.287 \mathrm{mmol} \mathrm{g}^{-1} \mathrm{Pt}^{-1}\right)$. Therefore, it could be concluded that Pt(Iv) was able to be present as the stable and active Pt species when the preparation temperature was increased to $78{ }^{\circ} \mathrm{C}$. This hypothesis is consistent with the UV/Vis spectra of the residual Pt solutions of $\mathrm{SiO}_{2}$-DTPA-Pt prepared at different internal temperatures in ethanol. As shown in Fig. $\mathrm{S} 3, \uparrow$ it could be observed that the absorbance at $265 \mathrm{~nm}$ gradually decreased and the absorbance at $243 \mathrm{~nm}$ appeared as the preparation temperature increased from $25{ }^{\circ} \mathrm{C}$ to $78{ }^{\circ} \mathrm{C}$. As we can see from Section 3.1.4, the absorbance of $\mathrm{Pt}$ (Iv) at $265 \mathrm{~nm}$ was consistent with that of samples prepared at $25{ }^{\circ} \mathrm{C}$, while the absorbance at $243 \mathrm{~nm}$ for the Pt prepared at $78{ }^{\circ} \mathrm{C}$ was consistent with the absorbance of $\mathrm{Pt}$ particles reported before. ${ }^{21}$ These results indicate that the catalytic activity is dependent on the preparation temperature; when the temperature increases to $78{ }^{\circ} \mathrm{C}$, the yield increases to the maximum, which might be caused by the conversion of $\mathrm{Pt}$ (Iv) to Pt particles.

The effect of preparation solvents including ethanol, $i$ propanol, $n$-butanol and $n$-hexanol on the catalytic activity was investigated. As in Section 2.3.3, we prepared $\mathrm{SiO}_{2}$-DTPA-Pt at $78{ }^{\circ} \mathrm{C}$ using different solvents. The results (Table 4) suggest that the catalytic activity for $\mathrm{SiO}_{2}$-DTPA-Pt is largely related to the synthetic solvents. It was revealed that catalysts prepared in three other solvents had low catalytic activities (39.1\%, 46.0\% and $8.5 \%$ in $i$-propanol, $n$-butanol and $n$-hexanol respectively) while the yield was $99.6 \%$ using ethanol as the immobilized solvent. As shown in Fig. S4, $\uparrow$ the UV/Vis spectra of the residual Pt solutions for $\mathrm{SiO}_{2}$-DTPA-Pt prepared with different solvents indicate that the absorbance of Pt at $243 \mathrm{~nm}$ using ethanol as the solvent was consistent with the absorbance of Pt particles reported before. ${ }^{21}$ Meanwhile, the absorbance was still at $265 \mathrm{~nm}$ when using $n$-butanol as the preparation solvent, which indicated that the Pt was immobilized on the $\mathrm{SiO}_{2}$-DTPA in the form of Pt(Iv). The absorbance of Pt increased to $277 \mathrm{~nm}$ when the preparation solvent was $n$-hexanol and disappeared when using $i$-propanol as the solvent which indicated that the $\mathrm{Pt}$

Table 2 Comparison of the hydrosilylation activities of immobilized Pt catalysts

\begin{tabular}{|c|c|c|c|c|c|c|c|}
\hline \multicolumn{2}{|l|}{ Catalyst } & \multicolumn{5}{|c|}{ Yield $(\%)^{a}$} & \multirow[b]{2}{*}{$\operatorname{TOF}^{b}\left(\mathrm{~s}^{-1}\right)$} \\
\hline Type & $\begin{array}{l}\text { Platinum content } \\
\left(\mathrm{mmol} \mathrm{g}^{-1}\right)\end{array}$ & $0.5 \mathrm{~h}$ & $1 \mathrm{~h}$ & $2 \mathrm{~h}$ & $3 \mathrm{~h}$ & $4 \mathrm{~h}$ & \\
\hline $\mathrm{SiO}_{2}$-DTPA-Pt & 0.287 & 90.3 & 94.3 & 95.9 & 99.1 & 99.6 & 1.79 \\
\hline $\mathrm{SiO}_{2-}-\mathrm{NTA}-\mathrm{Pt}$ & 0.150 & 52.5 & 87.2 & 88.8 & 90.2 & 94.4 & 1.27 \\
\hline $\mathrm{SiO}_{2}-\mathrm{SA}-\mathrm{Pt}$ & 0.118 & 7.5 & 17.7 & 33.8 & 80.3 & 97.1 & 0.14 \\
\hline
\end{tabular}

${ }^{a}$ Conditions: Pt amount: $\mathrm{SiO}_{2}$-DTPA-Pt: $2.8 \times 10^{-3} \mathrm{mmol} \mathrm{Pt}, \mathrm{SiO}_{2}$-NTA-Pt: $2.3 \times 10^{-3} \mathrm{mmol} \mathrm{Pt} \mathrm{SiO}_{2}$-SA-Pt: $2.9 \times 10^{-3} \mathrm{mmol} \mathrm{Pt}$; temperature: $60{ }^{\circ} \mathrm{C}$; adding order: silane is added to alkene. ${ }^{b}$ Turnover frequency measured at $0.5 \mathrm{~h}$. 
Table 3 Effect of the preparation temperature on catalytic activity of $\mathrm{SiO}_{2}$-DTPA-Pt

\begin{tabular}{|c|c|c|c|c|c|c|c|c|}
\hline \multicolumn{3}{|l|}{ Catalyst } & \multicolumn{5}{|c|}{ Yield (\%) ${ }^{a}$} & $\operatorname{TOF}^{b}\left(\mathrm{~s}^{-1}\right)$ \\
\hline 30 & 25 & 0.128 & 7.5 & 14.3 & 56.0 & 71.5 & 88.0 & 0.15 \\
\hline 50 & 43 & 0.133 & 11.8 & 22.3 & 73.4 & 88.3 & 89.4 & 0.23 \\
\hline 70 & 62 & 0.195 & 27.6 & 69.7 & 74.7 & 83.1 & 91.2 & 0.55 \\
\hline
\end{tabular}

${ }^{a}$ Conditions: Pt amount: $\mathrm{SiO}_{2}$-DTPA-Pt: $2.8 \times 10^{-3} \mathrm{mmol}$ Pt; temperature: $60{ }^{\circ} \mathrm{C}$; adding order: silane is added to alkene. ${ }^{b}$ Turnover frequency measured at $0.5 \mathrm{~h}$.

might be connected with DTPA functionalized silica in other forms. The solvents could affect the catalytic activity by influencing the valence state of Pt. In this case, ethanol was chosen as the optimal solvent for immobilizing Pt on the polycarboxylic acid-functionalized silica gel.

3.2.3 Effect of catalytic conditions on the immobilized Pt catalysts. Herein, we tried to find optimized catalytic conditions for alkane hydrosilylation catalyzed by the three Pt catalysts. In this case, the following conditions were investigated: the amount of the heterogeneous $\mathrm{Pt}$ catalyst, the reaction temperature, the reaction time, the adding order of the reactants and the ratio of reactants.

The alkene hydrosilylation activity with methyldichlorosilane catalyzed by immobilized Pt catalysts exhibited a strong dependence on temperature. Higher temperatures could give higher activity with a shorter time. ${ }^{41}$ The influence of the temperature $\left(40-80^{\circ} \mathrm{C}\right)$ on the catalytic activity of the polycarboxylic acid-functionalized silica supported Pt catalysts at different times was inspected. Fig. 5(A and B) show the yield of the products, dichloromethylhexylsilane, catalyzed by $\mathrm{SiO}_{2}$ DTPA-Pt and $\mathrm{SiO}_{2}$-NTA-Pt at different temperatures. $\mathrm{SiO}_{2}$-DTPAPt showed the highest activity, achieving the desired product in $99.6 \%$ yield with a $1.79 \mathrm{~s}^{-1}$ TOF at $60{ }^{\circ} \mathrm{C}$, and $\mathrm{SiO}_{2}$-NTA-Pt also showed high activity, achieving 1-hexyl-methyl-dichlorosilane in $94.4 \%$ yield with a $1.27 \mathrm{~s}^{-1}$ TOF. When the temperature was below or over $60^{\circ} \mathrm{C}$, the TOF of both $\mathrm{SiO}_{2}$-DTPA-Pt and $\mathrm{SiO}_{2}$ NTA-Pt was lower than that at $60^{\circ} \mathrm{C}$, with values of $0.25,0.63$, 1.07 and 0.95 at $40{ }^{\circ} \mathrm{C}, 50{ }^{\circ} \mathrm{C}, 70{ }^{\circ} \mathrm{C}$ and $80{ }^{\circ} \mathrm{C}$, respectively, for
$\mathrm{SiO}_{2}$-DTPA-Pt. Meanwhile, for $\mathrm{SiO}_{2}$-NTA-Pt, the TOF was 0.11, $0.24,0.93$ and 0.95 at $40{ }^{\circ} \mathrm{C}, 50{ }^{\circ} \mathrm{C}, 70{ }^{\circ} \mathrm{C}$ and $80{ }^{\circ} \mathrm{C}$, respectively. In this case, $60{ }^{\circ} \mathrm{C}$ gave the best result of all the temperatures evaluated $\left(40{ }^{\circ} \mathrm{C}\right.$ to $\left.80{ }^{\circ} \mathrm{C}\right)$, and temperature plays a significant role in the catalytic activity of the polycarboxylic acid-functionalized Pt catalysts.

In order to get a higher yield for 1-hexene hydrosilylation with methyldichlorosilane, a series of reaction times of $0.5 \mathrm{~h}$, $1 \mathrm{~h}, 2 \mathrm{~h}, 3 \mathrm{~h}$, and $4 \mathrm{~h}$ were investigated. As shown in Table 2, it is clearly observed that the yield of the products reached the maximum after $4 \mathrm{~h}$ (99.6\% for $\mathrm{SiO}_{2}$-DTPA-Pt and $94.4 \%$ for $\mathrm{SiO}_{2}$ NTA-Pt). The yield was $90.3 \%$ after the first $0.5 \mathrm{~h}$, and increased slowly to $94.3 \%(1 \mathrm{~h})$, then reached $99.6 \%$ after $4 \mathrm{~h}$ for $\mathrm{SiO}_{2}$ DTPA-Pt. In contrast, for $\mathrm{SiO}_{2}$-NTA-Pt, the yield was $52.5 \%$ after $0.5 \mathrm{~h}$ and increased rapidly to $87.2 \%$ from $0.5 \mathrm{~h}$ to $1 \mathrm{~h}$ and increased slowly after $1 \mathrm{~h}$, then reached the maximum of $94.4 \%$ after $4 \mathrm{~h}$. These results indicate that the reaction time plays an important role in the catalytic activity of the immobilized Pt catalysts, and $4 \mathrm{~h}$ was chosen as the reaction time for the experiments.

Hydrosilylable olefins are resistant to insertion into the Pt-Si bond and not to hydrosilylation if no excess silane is present. ${ }^{\mathbf{4 2}}$ Bearing this in mind, the effect of the ratio between the two reactants (methyldichlorosilane and 1-hexene) was inspected for $\mathrm{SiO}_{2}$-DTPA-Pt and $\mathrm{SiO}_{2}$-NTA-Pt, with ratios of $0.50: 1$, $1.00: 1,1.40: 1,1.80: 1,2.00: 1$, and $2.20: 1$. The data shown in Fig. 5(C) reveal that when the ratio of the reactants was $0.50: 1$, the yield was the lowest $(49.52 \%)$ for $\mathrm{SiO}_{2}$-DTPA-Pt

Table 4 Effect of the preparation solvent on the catalytic activity of $\mathrm{SiO}_{2}$-DTPA-Pt

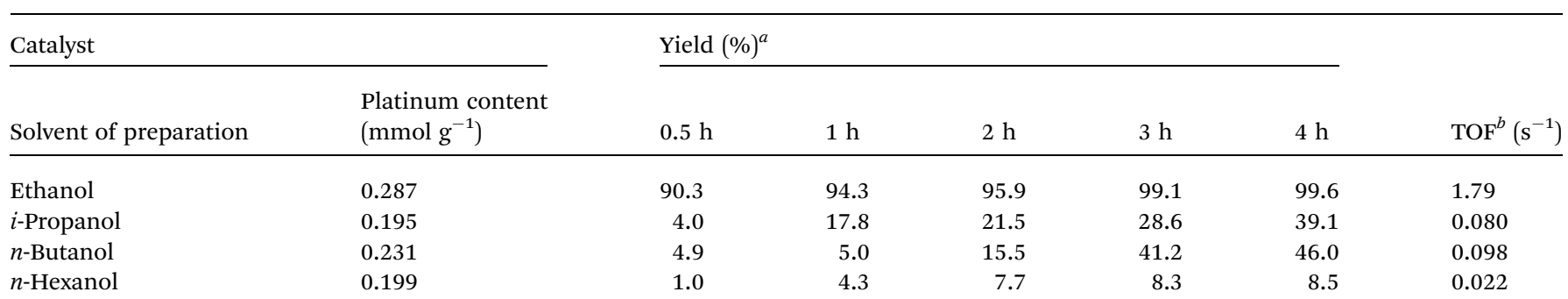

${ }^{a}$ Conditions: Pt amount: $\mathrm{SiO}_{2}$-DTPA-Pt: $2.8 \times 10^{-3} \mathrm{mmol} \mathrm{Pt}$; temperature: $60{ }^{\circ} \mathrm{C}$; adding order: silane is added to alkene. ${ }^{b}$ Turnover frequency measured at $0.5 \mathrm{~h}$. 


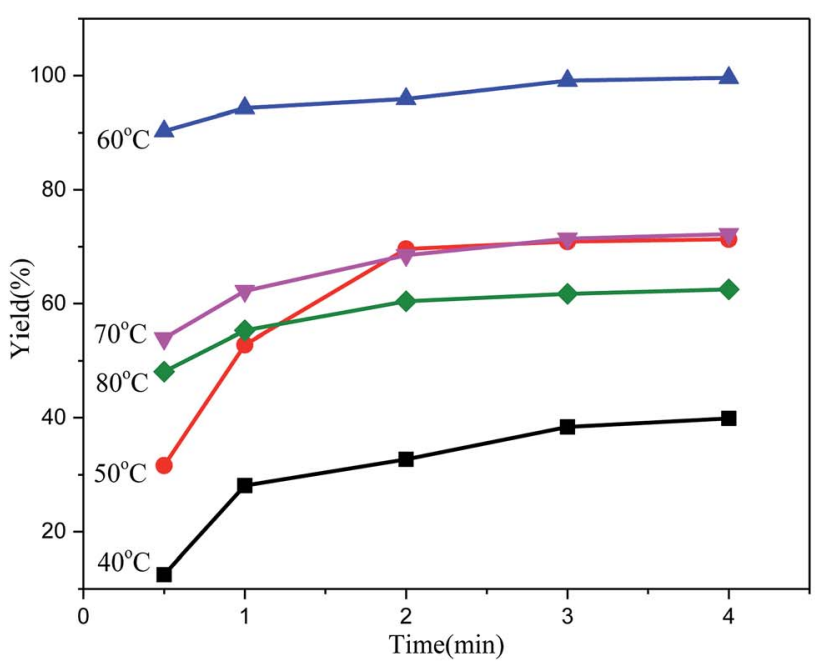

(A)

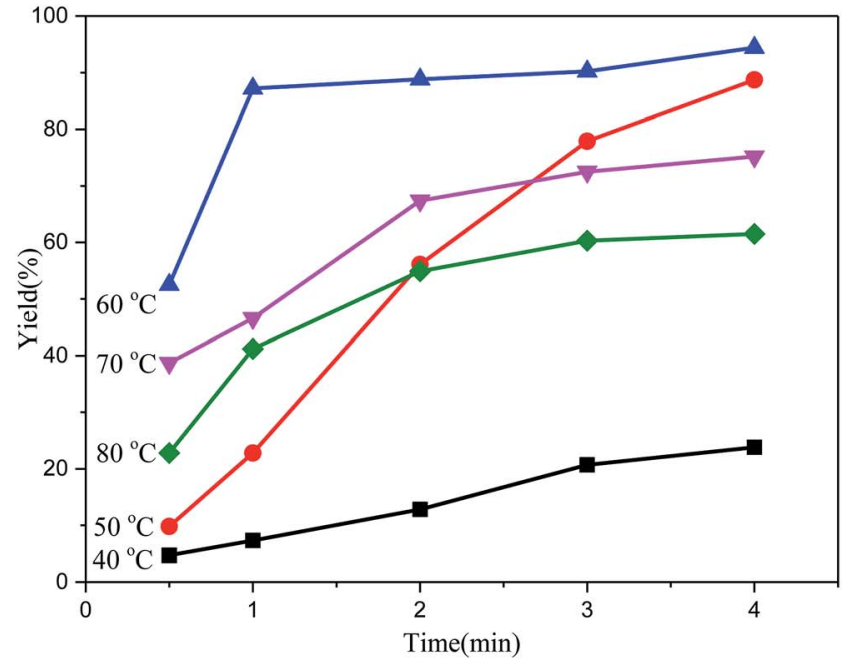

(B)

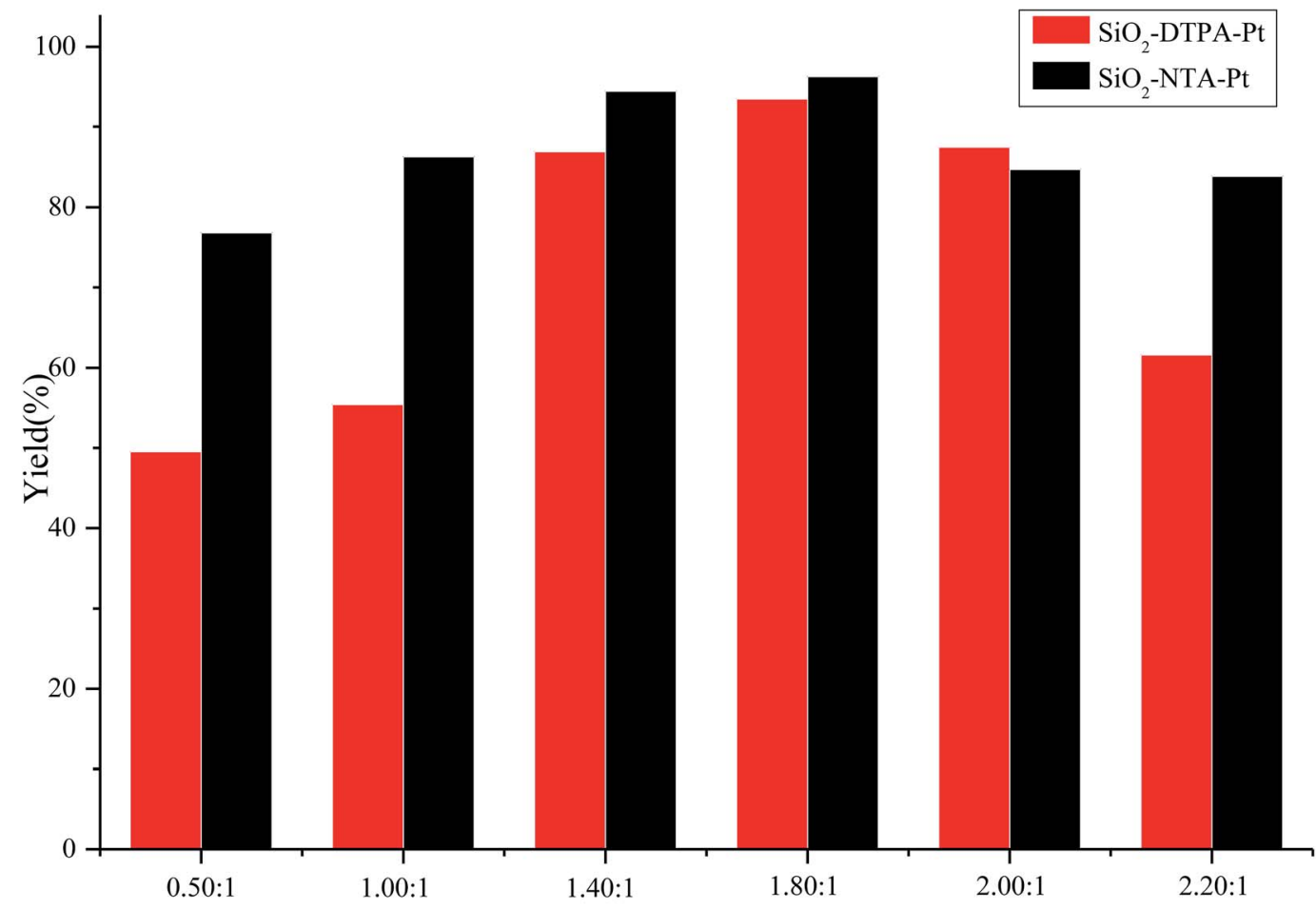

The molar ratio of methyldichlorosilane and 1-hexene

\section{(C)}

Fig. 5 The yield of the product $(\%)$ vs. temperature $\left({ }^{\circ} \mathrm{C}\right)$ at different times for 1-hexane hydrosilylation with methyldichlorosilane catalyzed by $\mathrm{SiO}_{2}$-DTPA-Pt (A) and $\mathrm{SiO}_{2}-\mathrm{NTA}-\mathrm{Pt}(\mathrm{B})$. The yield (\%) vs. reactant ratio for 1-hexane hydrosilylation with methyldichlorosilane catalyzed by $\mathrm{SiO}_{2}-$ DTPA-Pt and $\mathrm{SiO}_{2}-\mathrm{NTA}-\mathrm{Pt}(\mathrm{C})$. Conditions: (A and B) Pt amount: $\mathrm{SiO}_{2}-\mathrm{DTPA}-\mathrm{Pt}: 2.8 \times 10^{-3} \mathrm{mmol}$ Pt, $\mathrm{SiO}_{2}-\mathrm{NTA}-\mathrm{Pt}: 2.3 \times 10^{-3} \mathrm{mmol}$ Pt; time: $0.5 \mathrm{~h}, 1 \mathrm{~h}, 2 \mathrm{~h}, 3 \mathrm{~h}$ and $4 \mathrm{~h}$; temperature: $40,50,60,70$ and $80^{\circ} \mathrm{C}$; adding order: silane is added to the alkene. (C) The ratios of silane and alkene were $0.50: 1,1.00: 1,1.40: 1,1.80: 1,2.00: 1$ and $2.20: 1$. 
because of the residual 1-hexane. The yield of the dichloromethylhexylsilane increased from $55.41 \%$ to $93.45 \%$ as the ratio rose from $1.00: 1$ to $1.80: 1$. When the ratio continually increased, the yields of the product dropped from $87.49 \%$ to $81.62 \%$. Meanwhile for $\mathrm{SiO}_{2}-\mathrm{NTA}-\mathrm{Pt}$, the variation trend was similar to that for $\mathrm{SiO}_{2}$-DTPA-Pt, and it had the highest activity when the ratio was $1.80: 1$. Therefore, we used the ratio of $1.80: 1$ for the alkene hydrosilylation.

Results from the experiments with $\mathrm{SiO}_{2}$-DTPA-Pt or $\mathrm{SiO}_{2}$ NTA-Pt and those previously described ${ }^{31}$ for $\mathrm{SiO}_{2}$-EDTA-Pt showed that the hydrosilylation conditions such as reaction time, reaction temperature, and the ratio of reactants were similar for the APCA-functionalized silica supported Pt catalysts. In view of this, the reaction conditions for $\mathrm{SiO}_{2}-\mathrm{SA}-\mathrm{Pt}$ were the same as those for $\mathrm{SiO}_{2}$-DTPA-Pt and $\mathrm{SiO}_{2}$-NTA-Pt except for the catalyst dosage and the additive sequence of reactants.

The amount of the heterogeneous Pt catalyst plays a vital role in the catalytic activity. Therefore, the effect of the amount of the Pt catalyst on alkene hydrosilylation was inspected for these three immobilized Pt catalysts. The results revealed that the maximum yield reached $99.8 \%, 98.5 \%$ and $97.1 \%$ respectively for $\mathrm{SiO}_{2}$-DTPA-Pt $\left(2.8 \times 10^{-3} \mathrm{mmol} \mathrm{Pt}\right), \mathrm{SiO}_{2}$-NTA-Pt $(2.3$ $\left.\times 10^{-3} \mathrm{mmol} \mathrm{Pt}\right)$ and $\mathrm{SiO}_{2}$-SA-Pt $\left(2.9 \times 10^{-3} \mathrm{mmol} \mathrm{Pt}\right)$. The variation trend of these respective catalytic activities affected by catalytic dosage was similar for these three catalysts. When catalysts were used that contained less $\mathrm{Pt}$, i.e., $1.4 \times$ $10^{-3} \mathrm{mmol}$ for $\mathrm{SiO}_{2}$-DTPA-Pt $(37.0 \%), 7.5 \times 10^{-4} \mathrm{mmol}$ for $\mathrm{SiO}_{2}$-NTA-Pt $(62.4 \%)$ and $1.18 \times 10^{-3} \mathrm{mmol}$ for $\mathrm{SiO}_{2}$-SA-Pt $(32.8 \%)$, the yields were lower. These results indicate that the yields of the products of alkene hydrosilylation catalyzed by the polycarboxylic acid functionalized silica supported $\mathrm{Pt}$ catalysts were strongly dependent on the amount of heterogeneous Pt catalyst. A lower amount of Pt catalyst may lead to more by-products and limit the catalytic activity of the immobilized Pt catalysts.

The Chalk-Harrod mechanism was firstly proposed for alkene hydrosilylation catalyzed by Pt catalyst. ${ }^{43}$ For the mechanism, the alkene was coordinated to the center of $\mathrm{Pt}$ to form an alkene-Pt complex, then, the silane was introduced to the alkene-Pt complex for oxidative addition. The coordinated olefin was inserted into the $\mathrm{Pt}-\mathrm{H}$ bond and the hydrosilylation product was eliminated by reduction. The step of inserting the olefin into the $\mathrm{Pt}-\mathrm{H}$ bond is rate-limiting in alkene hydrosilylation. ${ }^{44}$ Thus, the adding order of the reactants might have an effect on the hydrosilylation. In this case, the influence of the adding order of the reactants on the alkene hydrosilylation for these three immobilized Pt catalysts was inspected. As shown in Fig. 6, it was clearly revealed that the catalytic activity of the model reaction was largely dependent on the adding order of the reactants. The varied trends of the yields of reactions catalyzed by these three Pt catalysts were similar; when methyldichlorosilane was poured into the reaction after 1-hexene and the Pt catalyst were stirred for $30 \mathrm{~min}$, the yields of dichloromethylhexylsilane increased to $97.14 \%, 94.42 \%$ and $95.45 \%$ for $\mathrm{SiO}_{2}$-DTPA-Pt, $\mathrm{SiO}_{2}$-NTA-Pt and $\mathrm{SiO}_{2}-\mathrm{SA}-\mathrm{Pt}$, respectively. Meanwhile, the yields decreased to $82.5 \%, 90.0 \%$ and $66.6 \%$

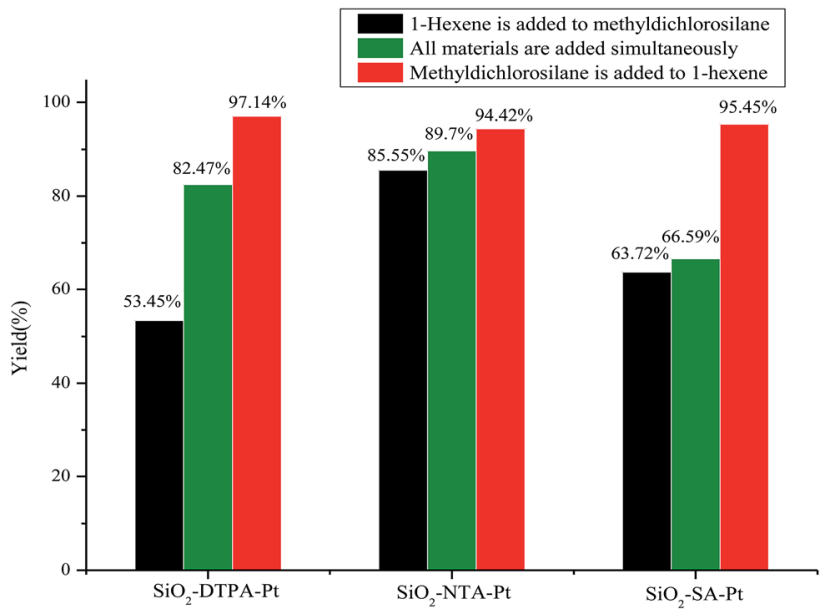

Fig. 6 Effect of the adding order of reactants on the yield of product for $\mathrm{SiO}_{2}$-DTPA-Pt, $\mathrm{SiO}_{2}-\mathrm{NTA}-\mathrm{Pt}$ and $\mathrm{SiO}_{2}-\mathrm{SA}-\mathrm{Pt}$. Conditions: $\mathrm{Pt}$ amount: $\mathrm{SiO}_{2}$-DTPA-Pt: $2.8 \times 10^{-3} \mathrm{mmol}$ Pt, $\mathrm{SiO}_{2}$-NTA-Pt: $2.3 \times$ $10^{-3} \mathrm{mmol} P t, \mathrm{SiO}_{2}-\mathrm{SA}-\mathrm{Pt}: 2.9 \times 10^{-3} \mathrm{mmol} \mathrm{Pt}$. Adding order: silane is added to alkene, all reactants are added simultaneously, alkene is added to silane.

when the reactants were added to the system at the same time and the yields reduced to $53.5 \%, 85.6 \%$ and $63.7 \%$ when 1 hexene was poured into the reaction after methyldichlorosilane and the Pt catalyst were stirred for $30 \mathrm{~min}$. These results indicate that the adding order of the reactants is a predominant influence in alkene hydrosilylation. A plausible catalytic mechanism for polycarboxylic acid-functionalized Pt catalysts is shown in Fig. 7. The mixture of Pt catalyst and alkene at a certain temperature can activate the double bond, and form the alkene-Pt complex. The olefin could then be inserted into the $\mathrm{Pt}-\mathrm{H}$ bond more easily and could improve the catalytic activity of the Pt catalyst.

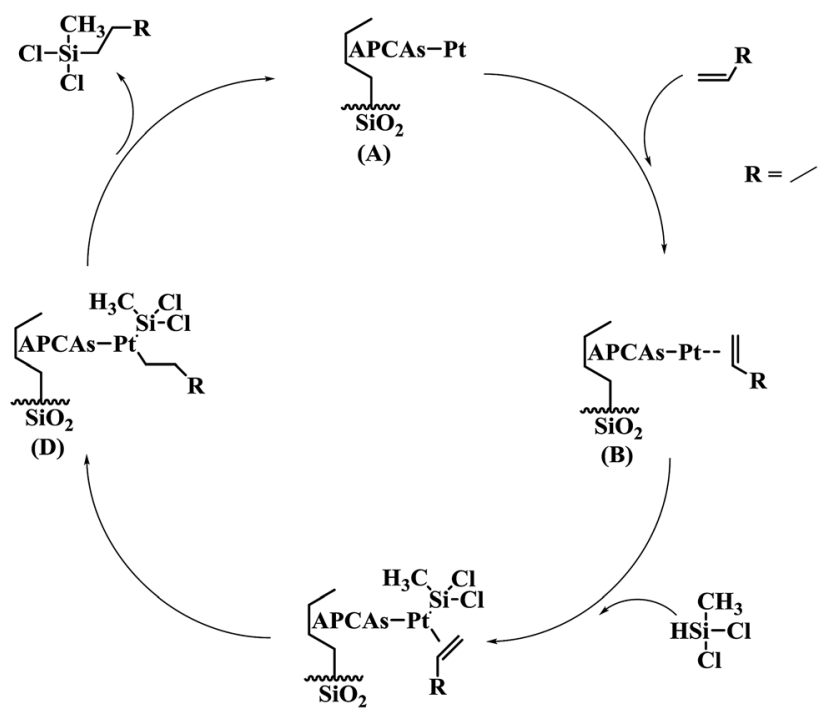

Fig. 7 A plausible catalytic mechanism for the polycarboxylic acidfunctionalized Pt catalysts. 


\subsection{The applicability of $\mathrm{SiO}_{2}-\mathrm{DTPA}-\mathrm{Pt}, \mathrm{SiO}_{2}-\mathrm{NTA}-\mathrm{Pt}$ and $\mathrm{SiO}_{2}-$} SA-Pt

As shown in Fig. 8, an array of substituted linear and ring type alkenes were used to investigate the applicability of the polycarboxylic acid-functionalized silica supported Pt catalysts. The catalytic products were analyzed using ${ }^{1} \mathrm{H}$ NMR.

The product of reactions using 1-heptene is dichloromethylheptylsilane, whose ${ }^{1} \mathrm{H}$ NMR spectrum is shown in Fig. S6A. $\uparrow$ The conversion of 1-heptene catalyzed by $\mathrm{SiO}_{2}$-DTPAPt, $\mathrm{SiO}_{2}$-NTA-Pt and $\mathrm{SiO}_{2}$-SA-Pt was $98.9 \%, 98.8 \%$ and $97.9 \%$, respectively, and the selectivity was $99 \%, 99 \%$ and $99 \%$, respectively, which is better than the selectivity of homogeneous platinum catalyst (94\%). The ${ }^{1} \mathrm{H}$ NMR spectrum of the product for 1-octene is shown in Fig. S6B $\dagger$ and agreed with that of standard dichloromethyloctylsilane. The conversion of 1-octene catalyzed by $\mathrm{SiO}_{2}$-DTPA-Pt, $\mathrm{SiO}_{2}$-NTA-Pt and $\mathrm{SiO}_{2}$-SA-Pt was 98.6\%, 98.1\% and $97.0 \%$, respectively, and the selectivity was $99 \%, 99 \%$ and $99 \%$, respectively, which is better than the selectivity of homogeneous platinum catalyst (95\%). The product of 1-decene was dichlorodecylmethylsilane, and the ${ }^{1} \mathrm{H}$ NMR spectrum is shown in Fig. S6C. $\dagger$ The conversion of 1decene catalyzed by $\mathrm{SiO}_{2}$-DTPA-Pt, $\mathrm{SiO}_{2}$-NTA-Pt and $\mathrm{SiO}_{2}$-SA-Pt was $97.8 \%, 97.7 \%$ and $97.1 \%$, respectively, and the selectivity was $99 \%$, 99\% and $99 \%$, respectively, which is better than the selectivity of homogeneous platinum catalyst (95\%). The product of 1-dodecene was dichlorododecylmethylsilane, whose ${ }^{1} \mathrm{H}$ NMR spectrum is shown in Fig. S6D. $\dagger$ The conversion of 1dodecene catalyzed by $\mathrm{SiO}_{2}$-DTPA-Pt, $\mathrm{SiO}_{2}$-NTA-Pt and $\mathrm{SiO}_{2}$-SAPt was $97.8 \%, 97.7 \%$ and $97.1 \%$, respectively, and the selectivity was $99 \%, 98 \%$ and $99 \%$, respectively, which is better than the selectivity of homogeneous platinum catalyst (95\%). The product of 1-tetradecylene was dichloromethyltetradecylsilane, whose ${ }^{1} \mathrm{H}$ NMR spectrum is shown in Fig. S6E. $\uparrow$ The conversion of 1-tetradecylene catalyzed by $\mathrm{SiO}_{2}$-DTPA-Pt, $\mathrm{SiO}_{2}$-NTA-Pt and $\mathrm{SiO}_{2}$-SA-Pt was $98.1 \%, 92.3 \%$ and $93.2 \%$, respectively, and the selectivity was $99 \%, 99 \%$ and $99 \%$, respectively, which is better than the selectivity of homogeneous platinum catalyst (95\%). The ${ }^{1} \mathrm{H}$ NMR spectrum of the product for 1-hexadecene is shown in Fig. S6F. $\uparrow$ The conversion of 1-hexadecene catalyzed by $\mathrm{SiO}_{2}-$ DTPA-Pt, $\mathrm{SiO}_{2}$-NTA-Pt and $\mathrm{SiO}_{2}$-SA-Pt was $95.0 \%, 93.4 \%$ and $94.0 \%$, respectively, and the selectivity was $99 \%, 98 \%$ and $97 \%$, respectively, which is better than the selectivity of homogeneous

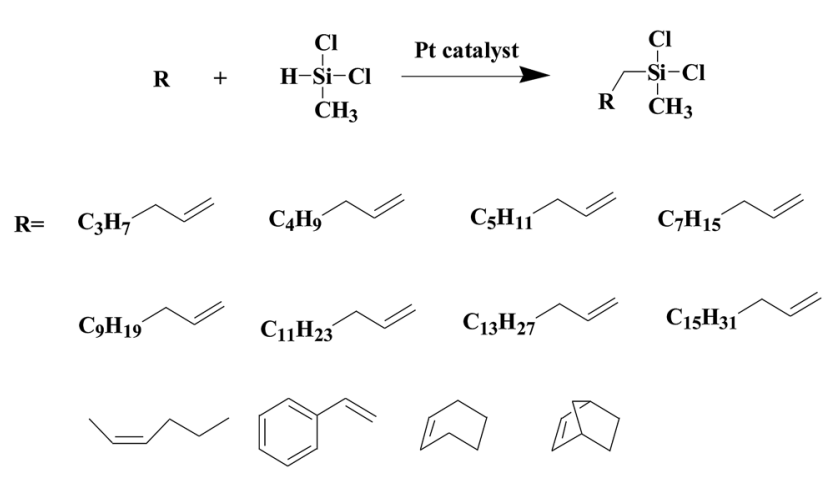

Fig. 8 The substrate scope of the hydrosilylation reaction. platinum catalyst $(94 \%)$. The product of 1-octadecene was dichloromethyloctadecylsilane, whose ${ }^{1} \mathrm{H}$ NMR spectrum is shown in Fig. S6G. $\dagger$ The conversion of 1-octadecene catalyzed by $\mathrm{SiO}_{2}$-DTPA-Pt, $\mathrm{SiO}_{2}$-NTA-Pt and $\mathrm{SiO}_{2}$-SA-Pt was 95.0\%, 93.4\% and $94.0 \%$, respectively, and the selectivity was $99 \%, 99 \%$ and $99 \%$, respectively, which is apparently better than the selectivity of homogeneous platinum catalyst $(87 \%)$. The product of styrene is dichloromethylphenethylsilane, whose ${ }^{1} \mathrm{H}$ NMR spectrum is shown in Fig. S6H. $\dagger^{45}$ The conversion of styrene catalyzed by $\mathrm{SiO}_{2}$-DTPA-Pt, $\mathrm{SiO}_{2}$-NTA-Pt and $\mathrm{SiO}_{2}$-SA-Pt was 95.5\%, 98.8\% and $95.7 \%$, respectively, and the selectivity was $99 \%, 99 \%$ and $99 \%$, respectively, which is apparently better than the selectivity of homogeneous platinum catalyst (63\%).

The above data suggest that these three immobilized Pt catalysts could also catalyze the hydrosilylation of other linear alkenes effectively. Linear terminal olefins gave very good yields of the corresponding silylated products (Table 5, entries 1 to 8 ) and had high selectivity.

Little attention has been paid to the hydrosilylation of internal double bonds so far, which are generally known to be far less reactive toward hydrosilylation than terminal olefins. ${ }^{\mathbf{4 6}}$ But for our research, we tried to use the immobilized platinum catalysts to catalyze the hydrosilylation of internal double bonds and chose cis-hex-2-ene as a model compound. In GC, the product, dichloromethylhexylsilane, appeared at $12.724 \mathrm{~min}$, which was separated well from cis-hex-2-ene at $3.001 \mathrm{~min}$. High conversion was achieved using an internal olefin (Table 5, entry 9 for cis-hex-2-ene); the conversion of the internal olefin was 95.2\%, $92.7 \%$ and $92.3 \%$ for cis-hex-2-ene catalyzed by $\mathrm{SiO}_{2}$ DTPA-Pt, $\mathrm{SiO}_{2}$-NTA-Pt and $\mathrm{SiO}_{2}$-SA-Pt, respectively, which was superior to the $33 \%$ achieved by Karstedt's catalyst. ${ }^{44}$ High selectivities were also observed (99\%, 99\% and 99\%, respectively). These results indicate that these three immobilized $\mathrm{Pt}$ catalysts may potentially be used in the hydrosilylation reaction of internal olefins.

Norbornene and cyclohexene were used to test the catalytic activity of these three immobilized Pt catalysts for ring type alkenes. In GC, the products could be separated well from norbornene or cyclohexene. The conversion of cyclohexene catalyzed by $\mathrm{SiO}_{2}$-DTPA-Pt, $\mathrm{SiO}_{2}$-NTA-Pt and $\mathrm{SiO}_{2}$-SA-Pt was $30.4 \%, 22.0 \%$ and $22.4 \%$, respectively. However, cyclohexene was unable to undergo hydrosilylation catalyzed by Karstedt's catalyst. ${ }^{44}$ These results indicate that these three immobilized Pt catalysts are superior to homogeneous Pt catalysts for the hydrosilylation of cyclohexene and methyldichlorosilan. In contrast, high conversion (92.5\%, 90.0\% and $88.6 \%$ catalyzed by $\mathrm{SiO}_{2}$-DTPA-Pt, $\mathrm{SiO}_{2}$-NTA-Pt and $\mathrm{SiO}_{2}$-SA-Pt, respectively) and selectivity (100\%) were obtained for norbornene. The ${ }^{1} \mathrm{H}$ NMR spectrum of the product is shown in Fig. S6I. $\uparrow$ These results reveal that these three immobilized Pt catalysts were more active for the hydrosilylation of norbornene than that of cyclohexene. It appears that the substitution pattern at the $\alpha$-C or the possible agostic interaction of the bridging methylene protons of norbornene might exert a beneficial effect. The forced boat conformation of norbornene confers it with a higher reactivity than the chair conformation of cyclohexene. 
Table 5 Hydrosilylation of selected substrates

\begin{tabular}{|c|c|c|c|c|c|}
\hline Entry & Catalyst & Substrate & Product $^{c}$ & Yield (\%) ${ }^{a}$ & Selectivity $^{b}$ \\
\hline 1 & $\begin{array}{l}\mathrm{SiO}_{2} \text {-DTPA-Pt } \\
\mathrm{SiO}_{2} \text {-NTA-Pt } \\
\mathrm{SiO}_{2} \text {-SA-Pt }\end{array}$ & $\mathrm{C}_{4} \mathrm{HI9}_{9}$ & $\mathrm{C}_{4} \mathrm{H}_{9}^{\prime}$ & $\begin{array}{l}98.9 \\
98.8 \\
97.9\end{array}$ & $\begin{array}{l}99 \% \\
99 \% \\
99 \%\end{array}$ \\
\hline 2 & $\begin{array}{l}\mathrm{SiO}_{2} \text {-DTPA-Pt } \\
\mathrm{SiO}_{2} \text {-NTA-Pt } \\
\mathrm{SiO}_{2} \text {-SA-Pt }\end{array}$ & $\mathrm{C}_{5} \mathrm{H}_{11}$ & $\mathrm{C}_{5} \mathrm{H}_{11}$ & $\begin{array}{l}98.6 \\
98.1 \\
97.0\end{array}$ & $\begin{array}{l}99 \% \\
99 \% \\
99 \%\end{array}$ \\
\hline 3 & $\begin{array}{l}\mathrm{SiO}_{2} \text {-DTPA-Pt } \\
\mathrm{SiO}_{2} \text {-NTA-Pt } \\
\mathrm{SiO}_{2} \text {-SA-Pt }\end{array}$ & $\mathrm{C}_{7} \mathrm{H}_{15}$ & C & $\begin{array}{l}97.8 \\
97.7 \\
97.1\end{array}$ & $\begin{array}{l}99 \% \\
99 \% \\
99 \%\end{array}$ \\
\hline 4 & $\begin{array}{l}\mathrm{SiO}_{2} \text {-DTPA-Pt } \\
\mathrm{SiO}_{2} \text {-NTA-Pt } \\
\mathrm{SiO}_{2} \text {-SA-Pt }\end{array}$ & $\mathrm{C}_{9} \mathrm{H}_{19}$ & $\mathrm{C}_{9} \mathrm{H}_{19}$ & $\begin{array}{l}97.3 \\
95.1 \\
90.8\end{array}$ & $\begin{array}{l}99 \% \\
98 \% \\
99 \%\end{array}$ \\
\hline 5 & $\begin{array}{l}\mathrm{SiO}_{2} \text {-DTPA-Pt } \\
\mathrm{SiO}_{2} \text {-NTA-Pt } \\
\mathrm{SiO}_{2} \text {-SA-Pt }\end{array}$ & $\mathrm{C}_{11} \mathrm{H}_{23}$ & $\mathrm{C}_{11} \mathrm{H}_{23}$ & $\begin{array}{l}98.1 \\
92.3 \\
93.2\end{array}$ & $\begin{array}{l}99 \% \\
99 \% \\
99 \%\end{array}$ \\
\hline 6 & $\begin{array}{l}\mathrm{SiO}_{2} \text {-DTPA-Pt } \\
\mathrm{SiO}_{2} \text {-NTA-Pt } \\
\mathrm{SiO}_{2} \text {-SA-Pt }\end{array}$ & $\mathrm{C}_{13} \mathrm{H}_{27}$ & $\mathbf{C}_{13} \mathbf{H}_{27}$ & $\begin{array}{l}95.0 \\
93.4 \\
94.0\end{array}$ & $\begin{array}{l}97 \% \\
98 \% \\
97 \%\end{array}$ \\
\hline 7 & $\begin{array}{l}\mathrm{SiO}_{2} \text {-DTPA-Pt } \\
\mathrm{SiO}_{2} \text {-NTA-Pt } \\
\mathrm{SiO}_{2} \text {-SA-Pt }\end{array}$ & $\mathrm{C}_{15} \mathrm{H}_{31}$ & $\mathrm{C}_{15} \mathrm{H}_{3}$ & $\begin{array}{l}93.5 \\
93.1 \\
91.6\end{array}$ & $\begin{array}{l}99 \% \\
99 \% \\
99 \%\end{array}$ \\
\hline 8 & $\begin{array}{l}\mathrm{SiO}_{2} \text {-DTPA-Pt } \\
\mathrm{SiO}_{2} \text {-NTA-Pt } \\
\mathrm{SiO}_{2} \text {-SA-Pt }\end{array}$ & & & $\begin{array}{l}95.5 \\
98.8 \\
95.7\end{array}$ & $\begin{array}{l}99 \% \\
99 \% \\
99 \%\end{array}$ \\
\hline 9 & $\begin{array}{l}\mathrm{SiO}_{2} \text {-DTPA-Pt } \\
\mathrm{SiO}_{2} \text {-NTA-Pt } \\
\mathrm{SiO}_{2} \text {-SA-Pt }\end{array}$ & & $\mathrm{C}_{3} \mathrm{H}$ & $\begin{array}{l}95.2 \\
92.7 \\
92.3\end{array}$ & $\begin{array}{l}99 \% \\
99 \% \\
99 \%\end{array}$ \\
\hline 10 & $\begin{array}{l}\mathrm{SiO}_{2} \text {-DTPA-Pt } \\
\mathrm{SiO}_{2} \text {-NTA-Pt } \\
\mathrm{SiO}_{2} \text {-SA-Pt }\end{array}$ & & CI I & $\begin{array}{l}92.5 \\
90.0 \\
88.6\end{array}$ & $\begin{array}{l}100 \% \\
100 \% \\
100 \%\end{array}$ \\
\hline 11 & $\begin{array}{l}\mathrm{SiO}_{2} \text {-DTPA-Pt } \\
\mathrm{SiO}_{2} \text {-NTA-Pt } \\
\mathrm{SiO}_{2} \text {-SA-Pt }\end{array}$ & & $\mathrm{C}$ & $\begin{array}{l}30.4 \\
22.0 \\
22.4\end{array}$ & $\begin{array}{l}100 \% \\
100 \% \\
100 \%\end{array}$ \\
\hline
\end{tabular}

${ }^{a}$ Conditions: Pt amount: $\mathrm{SiO}_{2}$-DTPA-Pt: $2.8 \times 10^{-3} \mathrm{mmol} \mathrm{Pt}^{b} \mathrm{SiO}_{2}$-NTA-Pt: $2.3 \times 10^{-3} \mathrm{mmol} \mathrm{Pt} \mathrm{SiO}_{2}$-SA-Pt: $2.9 \times 10^{-3} \mathrm{mmol} \mathrm{Pt}$; temperature: $60{ }^{\circ} \mathrm{C}$; time: $4 \mathrm{~h}$; adding order: silane is added to alkene. ${ }^{b}$ Selectivity was determined using GC. ${ }^{c}$ Products were determined using ${ }^{1} \mathrm{H}$ NMR. Please see Fig. S4 for the relevant NMR spectra.

\subsection{The reusability of $\mathrm{SiO}_{2}-\mathrm{DTPA}-\mathrm{Pt}, \mathrm{SiO}_{2}-\mathrm{NTA}-\mathrm{Pt}$ and $\mathrm{SiO}_{2}-$} SA-Pt

To investigate the reusability of polycarboxylic acidfunctionalized silica supported Pt catalysts, 1-hexene hydrosilylation with methyldichlorosilane was used to do the recycling experiments. After each catalytic reaction for these three Pt catalysts, the reactants could be separated by centrifuging them from the system. Then, the heterogeneous Pt catalysts could be held in the original system and reused in the next catalytic reaction without any processing. As shown in Fig. 9, the results reveal that $\mathrm{SiO}_{2}$-DTPA-Pt shows a very good activity over thirteen catalytic runs with a small loss in the yield of 1-hexyl- methyldichlorosilane (80\% after thirteen catalytic runs). Meanwhile, $\mathrm{SiO}_{2}$-NTA-Pt could be reused seven times and the yield of the final run was $82 \%$. However, the yield of 1-hexylmethyldichlorosilane drastically dropped over the three runs (96.9\%, 62.8\% and $30.9 \%)$ for $\mathrm{SiO}_{2}$-SA-Pt. It was found in leaching experiments that the Pt content of $\mathrm{SiO}_{2}$-DTPA-Pt decreased from $5.59 \mathrm{wt} \%$ to $5.28 \mathrm{wt} \%$ after being reused 4 times, which indicates that the loss of Pt occurs during the reaction. The Pt content decreased to $4.94 \mathrm{wt} \%, 4.43 \mathrm{wt} \%$ and $3.86 \mathrm{wt} \%$ after being reused 7, 10 and 13 times, respectively. In other words, the average loss of Pt was approximately $1.44 \mathrm{ppm}$ in each reaction, which was lower than the active concentration 


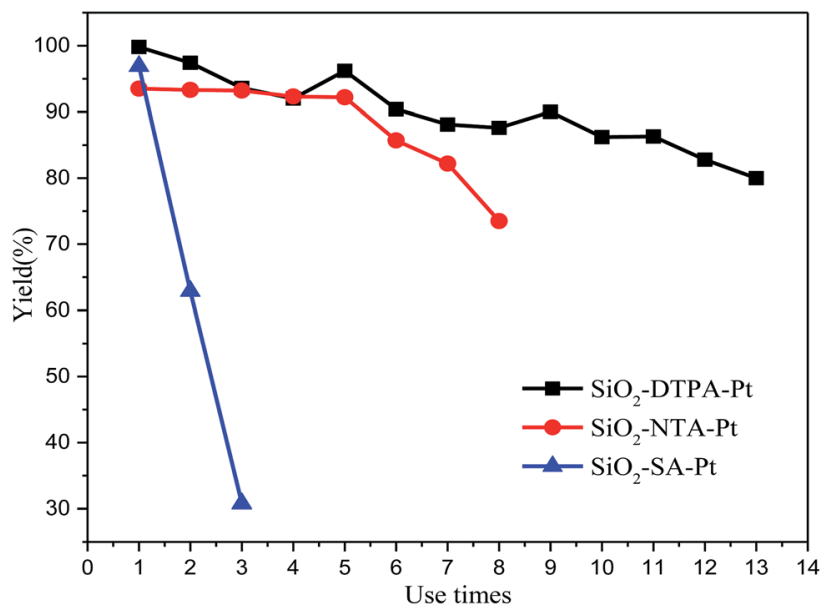

Fig. 9 Reuse cycles of $\mathrm{SiO}_{2}$-DTPA-Pt, $\mathrm{SiO}_{2}-\mathrm{NTA}-\mathrm{Pt}$ and $\mathrm{SiO}_{2}-\mathrm{SA}-\mathrm{Pt}$.

(i.e. $10 \mathrm{ppm}$ ) for homogeneous Pt catalysts. The loss of the Pt catalyst in each run was an important reason contributing to the decrease in the yield. However, the difference in the binding abilities of DTPA, NTA and SA may cause the difference in the reusability for these three immobilized Pt catalysts. DTPA had much stronger interactions with Pt than NTA and SA, and had little decrease in activity after repeated use.

\section{Conclusions}

A series of novel polycarboxylic acid-functionalized silica supported Pt catalysts was successfully synthesized in our work. The XPS results indicated the existence of charge transfer from Pt to the coordination atoms of DTPA, NTA and SA. These three new immobilized Pt catalysts were shown to have wide applications, high activity, selectivity and reusability for alkene hydrosilylation. Among them, $\mathrm{SiO}_{2}$-DTPA-Pt showed the best catalytic ability and could be reused 13 times with less loss of yield of the product because of the strong connections of DTPA with Pt. The three new polycarboxylic acid-functionalized Pt catalysts may potentially be used in industrial alkene hydrosilylation.

\section{Conflicts of interest}

There are no conflicts to declare.

\section{Abbreviations}

$\begin{array}{ll}\text { DTPA } & \text { Diethylenetriaminepentaacetic acid } \\ \text { DTPAD } & \text { Diethylenetriaminepentaacetic dianhydride } \\ \text { EDTA } & \text { Ethylenediaminetetraacetic acid } \\ \text { NTA } & \text { Nitrilotriacetic acid } \\ \text { SA } & \text { Succinic acid } \\ \text { AAS } & \text { Atomic absorption spectroscopy } \\ \text { IR } & \text { Infrared spectroscopy } \\ \text { NMR } & \text { Nuclear magnetic resonance } \\ \text { UV } & \text { Ultraviolet spectroscopy }\end{array}$

\begin{tabular}{|c|c|}
\hline TEM & Transmission electron micrographs \\
\hline HRTEM & $\begin{array}{l}\text { High resolution transmission electron } \\
\text { micrographs }\end{array}$ \\
\hline GC & Gas chromatography \\
\hline EDS & Energy dispersive X-ray spectrometer \\
\hline XPS & X-ray photoelectron spectroscopic \\
\hline APTES & $\gamma$-aminopropyltriethoxysilane \\
\hline $\mathrm{SiO}_{2}$-DTPA & DTPA-functionalized silica gel \\
\hline $\begin{array}{l}\mathrm{SiO}_{2} \text {-DTPA- } \\
\mathrm{Pt}\end{array}$ & $\mathrm{SiO}_{2}$-DTPA supported Pt \\
\hline $\mathrm{SiO}_{2}$-NTA & NTA-functionalized silica gel \\
\hline $\mathrm{SiO}_{2}$-NTA-Pt & $\mathrm{SiO}_{2}$-NTA supported Pt \\
\hline $\mathrm{SiO}_{2}-\mathrm{SA}$ & SA-functionalized silica gel \\
\hline $\mathrm{SiO}_{2}$-SA-Pt & $\mathrm{SiO}_{2}$-SA supported Pt \\
\hline TOF & turnover frequency \\
\hline
\end{tabular}

\section{Acknowledgements}

The authors are grateful for support from the National Natural Science Foundation of China (No. 21605112) and the Youth Fund of the Science and Technology Committee of Tianjin Municipal Government (No. 15JCQNJC43200).

\section{Notes and references}

1 J. L. Speier, Adv. Organomet. Chem., 1979, 17, 407-447.

2 M. Shelef, J. H. Jones, J. T. Kummer, K. Otto and E. E Weaver, Environ. Sci. Technol., 1971, 5(9), 790-798.

3 M. Itoh, K. Motoki, M. Saito, J. Iwamoto and M. Ken-Ichi, Bull. Chem. Soc. Jpn., 2009, 82(9), 1197-1202.

4 F. Y. Zhao, Y. Ikushima and M. Arai, J. Catal., 2004, 224(2), 479-483.

5 C. Exner, A. Pfaltz, M. Studer and H. U. Blaser, Adv. Synth. Catal., 2003, 345(11), 1253-1260.

6 M. A. Yoichi, T. Arakawa, H. Hocke and Y. Uozumi, Angew. Chem., Int. Ed., 2007, 119, 718-720.

7 J. Li, N. Wang, Z. H. Ma, Z. H. Hu and L. Y. Sun, Rare Met. Mater. Eng., 2013, 42(2), 259-262.

8 J. S. Rhee, R. M. Sneeringer and A. S. Penzias, Coord. Chem. Rev., 2011, 255(13), 1440-1459.

9 J. C. Stephen, Silicon, 2009, 1, 57-58.

10 B. Karstedt, US Pat. 3814730, 1973.

11 I. E. Markó, S. Stérin, O. Buisine, G. Mignani, P. Branlard, B. Tinan and J. P. Declercq, Science, 2002, 298(5591), 204206.

12 M. Poyatos, F. A. Maisse, B. L. Stephane and L. H. Gade, Organometallics, 2006, 25(10), 2634-2641.

13 K. Kaneda, K. Ebitani, T. Mizugaki and K. Mori, J. Cheminform., 2006, 79, 781-1016.

14 J. Li, C. H. Yang, L. Zhang and T. L. Ma, J. Organomet. Chem., 2011, 696(9), 1845-1849.

15 Y. Bai, J. Peng, J. Y. Li, G. Q. Lai and X. N. Li, Curr. Catal., 2012, 1, 180-185.

16 G. D. Thomas, R. Sayah, M. L. Zanota, S. Marrot, L. Veyre, C. Thieuleux and V. Meille, Chem. Commun., 2017, 53(20), 2962-2965. 
17 X. J. Cui, K. Junge, X. C. Dai, C. Kreyenschulte, M. P. Martina, W. Sebastian, F. Shi, B. Angelika and B. Matthias, ACS Cent. Sci., 2017, 3(6), 580-585.

18 Y. Fort, A. Silvestri and H. Graindorge, J. Mol. Catal. A: Chem., 1996, 112(2), 311-316.

19 H. T. Yang, Z. P. Fang, X. Y. Fu and L. F. Tong, Catal. Commun., 2008, 9(6), 1092-1095.

20 A. Kowalewska, J. Organomet. Chem., 2008, 693(12), 21932199.

21 Y. Bai, S. F. Zhang, Y. Deng, J. J. Peng, J. Y. Li, Y. Q. Hu and X. N. Li, J. Colloid Interface Sci., 2013, 394(1), 428-433.

22 Z. M. Michalska, K. Strzelec and J. W. Sobczak, J. Mol. Catal. A: Chem., 2000, 156(1), 91-102.

23 M. Chauhan, B. J. Hauck, L. P. Keller and P. Boudjouk, J. Organomet. Chem., 2002, 645, 1-13.

24 F. Y. Rao, S. J. Deng, C. Chen and N. Zhang, Catal. Commun., 2014, 46(5), 1-5.

25 A. Francisco, R. Buitrago, Y. Moglie, R. M. Javier, S. E. Antonio and Y. Miguel, J. Organomet. Chem., 2011, 696(1), 368-372.

26 B. Nowack, Environ. Sci. Technol., 2002, 36(19), 4009-4016.

27 S. D. N. Almeida and H. E. Toma, Hydrometallurgy, 2016, 161, 22-28.

28 Y. Shiraishi, G. Nishimura, H. Takayuki and I. Komasawa, Ind. Eng. Chem. Res., 2002, 41(20), 5065-5070.

29 A. Baraka, P. J. Hall and M. J. Heslop, J. Hazard. Mater., 2007, 140(1-2), 86-94.

30 O. Ikodiya, M. Uzoamaka and I. Ezeani, International Journal of Innovative Research and Development, 2017, 6, 117-127.

31 F. T. Li and Y. X. Li, J. Mol. Catal. A: Chem., 2016, 420, 254263.
32 M. Tülü and K. E. Geckeler, Polym. Int., 1999, 48, 909-914.

33 A. H. Mark and R. Edward, Sep. Sci. Technol., 2007, 42(2), 261-283.

34 K. Nakamoto, Sexually Transmitted Infections, 2008, 85(3), 182-186.

35 J. Greiser, T. Hagemann, T. Niksch, P. Traber, S. Kupfer, S. Gräfe, H. Görls, W. Weigand and M. Freesmeyer, Eur. J. Inorg. Chem., 2015, 24, 4125-4137.

36 Y. Q. An, M. Chen, Q. Xue and W. M. Liu, J. Colloid Interface Sci., 2007, 311(2), 507-513.

37 M. Luty-Blocho, M. Wojnicki, K. Paclawski and K. Fitzner, Chem. Eng. J., 2013, 226, 46-51.

38 R. F. Nie, D. Liang, L. Shen, J. Gao, P. Chen and Z. Y. Hou, Appl. Catal., B, 2012, 127, 212-220.

39 C. Zhang, T. Wang, X. Liu and Y. J. Ding, J. Mol. Catal. A: Chem., 2016, 424, 91-97.

40 C. Liu, G. Li, D. R. Kauffman, G. S. Pang and R. C. Jin, J. Colloid Interface Sci., 2014, 423(423), 123-128.

41 R. H. Hu, L. F. Zha and M. Z. Cai, Catal. Commun., 2010, 11, 563-566.

42 A. K. Roy and R. B. Taylor, J. Am. Chem. Soc., 2002, 124(32), 9510-9524.

43 A. J. Chalk and J. F. Harrod, J. Am. Chem. Soc., 1965, 87(1), 583-597.

44 T. K. Meister, K. Riener, P. Gigler, J. Stohrer, W. A. Herrmann and E. K. Fritz, ACS Catal., 2016, 6(2), 1274-1284.

45 B. J. Brisdon and A. M. Watts, J. Chem. Soc., Dalton Trans., 1985, 10(10), 2191-2194.

46 J. S. Rhee, R. M. Sneeringer and A. S. Penzias, Coord. Chem. Rev., 2011, 255(13), 1440-1459. 